\title{
In Situ Solid-Gas Reactivity of Nanoscaled Metal Borides from Molten Salt Synthesis
}

Guillaume Gouget, ${ }^{\dagger,}$ Damien P. Debecker, ${ }^{\nabla}$ Ara Kim, ${ }^{\dagger,}{ }^{\nabla}$ Giorgia Olivieri, ${ }^{\perp}$ Jean-Jacques

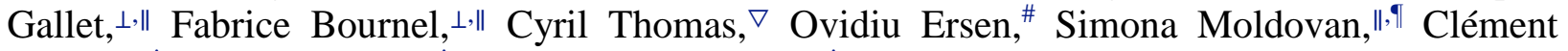
Sanchez, ${ }^{\dagger}$ Sophie Carenco, ${ }^{\dagger}$ and David Portehault $*, \dagger$

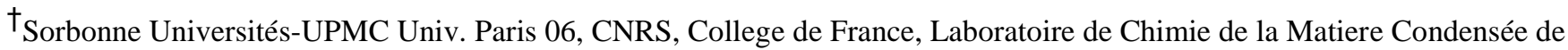 \\ Paris, 4 place Jussieu, F-75252 Paris Cedex 05, France \\ Université Catholique de Louvain, Institute of Condensed Matter \& Nanosciences, Molecules, Solids \& Reactivity, Place \\ Louis Pasteur 1, 1348 Louvain-la-Neuve, Belgium \\ ${ }^{\perp}$ Synchrotron SOLEIL L'Orme des Merisiers, Saint-Aubin, BP 48, 91192 Gif sur Yvette Cedex, France \\ "Sorbonne Universités, UPMC Univ. Paris 06, Laboratoire de Chimie Physique, Matière et Rayonnement, 4 place Jussieu, F-75252 \\ Paris Cedex 05, France

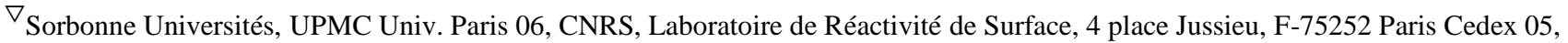 \\ France \\ \# Institut de Physique et Chimie des Matériaux de Strasbourg, CNRS, 23 Rue Loess, BP 43, F-67034 Strasbourg, France
}

\begin{abstract}
Metal borides have mostly been studied as bulk materials. The nanoscale provides new opportunities to investigate the properties of these materials, e.g., nanoscale hardening and surface reactivity. Metal borides are often considered stable solids because of their covalent character, but little is known on their behavior under a reactive atmosphere,

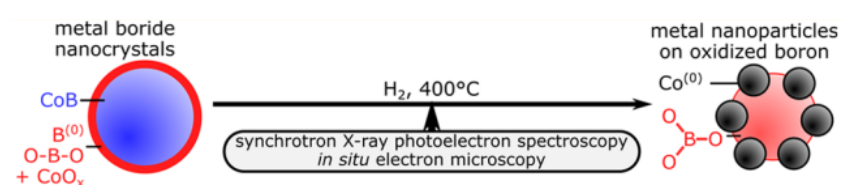
especially reductive gases. We use molten salt synthesis at $750{ }^{\circ} \mathrm{C}$ to provide cobalt monoboride $(\mathrm{CoB})$ nanocrystals embedded in an amorphous layer of cobalt(II) and partially oxidized boron as a model platform to study morphological, chemical, and structural evolutions of the boride and the superficial layer exposed to argon, dihydrogen $\left(\mathrm{H}_{2}\right)$, and a mixture of $\mathrm{H}_{2}$ and carbon dioxide $\left(\mathrm{CO}_{2}\right)$ through a multiscale in situ approach: environmental transmission electron microscopy, synchrotron-based nearambient-pressure X-ray photoelectron spectroscopy, and near-edge X-ray absorption spectroscopy. Although the material is stable under argon, $\mathrm{H}_{2}$ triggers at $400{ }^{\circ} \mathrm{C}$ decomposition of $\mathrm{CoB}$, leading to cobalt $(0)$ nanoparticles. We then show that $\mathrm{H}_{2}$ activates $\mathrm{CoB}$ for the catalysis of $\mathrm{CO}_{2}$ methanation. A similar decomposition process is also observed on $\mathrm{NiB}$ nanocrystals under oxidizing conditions at $300{ }^{\circ} \mathrm{C}$. Our work highlights the instability under reactive atmospheres of nanocrystalline cobalt and nickel borides obtained from molten salt synthesis. Therefore, we question the general stability of metal borides with distinct compositions under such conditions. These results shed light on the actual species in metal boride catalysis and provide the framework for future applications of metal borides in their stability domains.
\end{abstract}

\section{INTRODUCTION}

Synthetic routes toward nanocrystalline metal borides are drawing increasing interest ${ }^{1-8}$ because of the properties of these materials, which differ from those of other solids, including magnetism, plasmonics, thermoelectricity, superconductivity, and superhardness., ${ }^{2,9-18}$ Nanoscaled metal borides are also attractive as heterogeneous catalysts of the selective hydrogenation of various functional organic groups. ${ }^{8,19,20}$ Moreover, cobalt, nickel, iron, and palladium borides ${ }^{8}$ are currently considered for the production of hydrogen, by catalysis of the hydrolysis of sodium borohydride $\left(\mathrm{NaBH}_{4}\right)^{21,22}$ and electrocatalysis of the hydrogen evolution reaction. ${ }^{23-26}$ In all cases, the nanoscale provides a parameter to influence or enhance properties, but it has been only scarcely explored because of the difficulty in synthesizing nanoscaled metal borides. Assessing the chemical stability and structural evolution of these nanomaterials is of utmost importance to identify suitable temperature ranges for operation as thermo-electric materials, hard coatings, or heterogeneous catalysts, for instance. ${ }^{22,27}$ Such applications require chemical and thermal stability that is not met by readily available amorphous boride nanoparticles but should be strongly improved in crystalline nanoparticles. Although the stability of borides under air and inert atmospheres has been examined, ${ }^{1,13,28-31}$ compositional, structural, and morphological evolutions of nanocrystalline metal borides in contact with other gases, especially the reductive atmosphere encountered in catalytic processes, 
are unknown because of the scarcity of crystalline boride nanomaterials. ${ }^{1-8}$

Herein we use inorganic molten salts as media to synthesize crystalline cobalt and nickel monoboride $(\mathrm{CoB}$ and $\mathrm{NiB}$ ) nanoparticles embedded in an amorphous layer comprising cobalt(II) species and partially oxidized boron. ${ }^{5,6} \mathrm{We}$ then explore the reactivity of these nanomaterials, exposing high surface areas. Our multiscale in situ analytical methodology combines two techniques enabling studies under reactive atmospheres. First, environmental transmission electron microscopy (TEM) enables one to investigate the nanoscale morphology evolution at pressures of up to 1 bar. ${ }^{32,33}$ Second, ensembles of nanoparticles are analyzed by synchrotron-based nearambient-pressure X-ray photoelectron spectroscopy (NAPXPS $)^{34}$ and near-edge X-ray absorption spectroscopy (NEXAFS) to provide information on chemical and structural evolutions occurring at the surface and in the core of the material, respectively, under a few millibars of several gases, especially hydrogen. On $\mathrm{CoB}$, we demonstrate that the boride is surprisingly decomposed under reducing conditions, yielding cobalt particles at a relatively low temperature of $400{ }^{\circ} \mathrm{C}$. We then show that hydrogen treatment activates $\mathrm{CoB}$ for the catalysis of carbon dioxide $\left(\mathrm{CO}_{2}\right)$ methanation, through these cobalt $(0)$ species. Similar decomposition occurs in $\mathrm{NiB}$ nanocrystals exposed to oxidizing conditions, suggesting that this behavior may be generalized to many other metal boride nanomaterials under a reactive atmosphere, thus providing the frame for their future use as catalysts and functional coatings.

\section{RESULTS AND DISCUSSION}

CoB Nanoparticles Synthesized in Molten Salts. CoB nanocrystals were synthesized under argon at $750{ }^{\circ} \mathrm{C}$ from the reaction between cobalt(II) chloride $\left(\mathrm{CoCl}_{2}\right)$ and $\mathrm{NaBH}_{4}$ in a lithium chloride $(\mathrm{LiCl}) /$ potassium chloride $(\mathrm{KCl})$ mixture (45/ $55 \mathrm{wt} \%$; melting point of $353{ }^{\circ} \mathrm{C}$ ). After cooling to room temperature (RT), the frozen salt medium was washed with deionized water. A black powder was recovered and stored in air.

X-ray diffraction (XRD; Figure 1a) shows that $\mathrm{CoB}$ is the only crystalline phase. The apparent size is $14 \pm 2 \mathrm{~nm}$ according to the Scherrer formula. TEM and highresolution TEM (HRTEM; Figure 1b,c) reveal that the sample is composed of single-crystal $\mathrm{CoB}$ nanoparticles with diameters ranging from 4 to $20 \mathrm{~nm}$, in agreement with XRD. These particles are smaller than any other CoB nanoparticles reported in the literature to date (18-22 $\mathrm{nm}){ }^{35}$ The particles are dispersed in an amorphous matrix exhibiting a lower contrast and a 2-5 nm thickness. Highcontrast inclusions of ca. $1 \mathrm{~nm}$ (black arrows in Figure 1b) are detected in the amorphous matrix. Z-contrast pictures acquired by high-annular-angle dark-field detection in scanning TEM mode (STEM-HAADF; Figure 1d) highlight cobalt-rich regions as bright areas corresponding to the $\mathrm{CoB}$ nanoparticles and to subnanometric cobalt-rich inclusions in the amorphous layer. These latter species are not detected by XRD. Energy-dispersive X-ray analysis indicates that cobalt, boron, and oxygen are the only elements present in the material (data not shown). The measured composition of $\mathrm{Co}_{0.30} \mathrm{~B}_{0.53} \mathrm{O}_{0.17}$ is in accordance with the $\mathrm{Co} / \mathrm{B}$ ratio of 0.6 measured by inductively coupled plasma (ICP). On the basis of a previous study, oxygen is expected to be located in the amorphous matrix. ${ }^{5}$
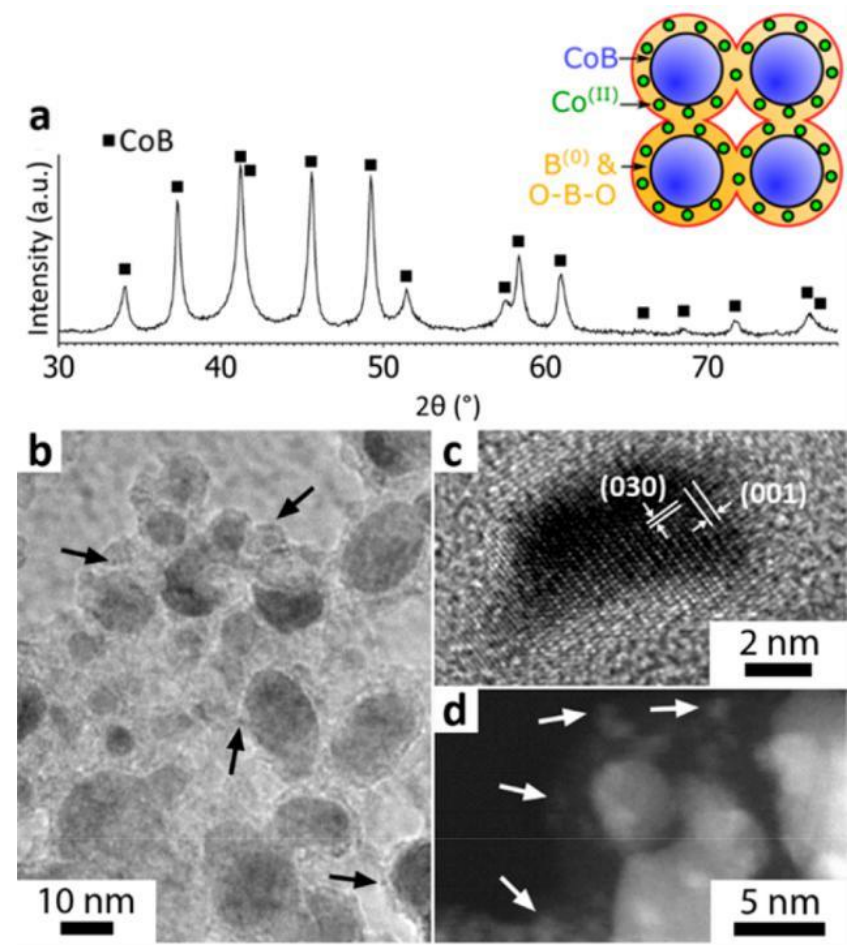

Figure 1. (a) Powder XRD pattern of a $\mathrm{CoB}$ sample synthesized in inorganic molten salts at $750{ }^{\circ} \mathrm{C}$ for $1.5 \mathrm{~h}$. Scheme of the sample nanostructure deduced from XRD, TEM, and XPS. (b) TEM picture of $\mathrm{CoB}$ nanoparticles embedded in an amorphous matrix. Black arrows highlight subnanometer inclusions in the matrix. (c) HRTEM picture of a $\mathrm{CoB}$ nanoparticle. (d) Z-contrast picture from STEM-HAADF. White arrows indicate bright cobalt-rich inclusions in the superficial layer.

Brunauer-Emmett- Teller analysis of the dinitrogen sorption isotherms indicates a specific surface area of 71 $\mathrm{m}^{2} \mathrm{~g}^{-1}$, more than twice the highest value reported in the literature $\left(32 \mathrm{~m}^{2} \mathrm{~g}^{-1}\right)$ for $\mathrm{CoB}$ materials. ${ }^{36}$ Compositional information on the superficial amorphous layer was further provided by XPS under ultrahigh vacuum (UHV; Figure 2). Using synchrotron-based radiation (TEMPO beamline at Synchrotron SOLEIL, Gif sur Yvette Cedex, France) enabled changing of the inelastic mean-free path of the photoelectron, and, hence, the depth of analysis, ${ }^{37-39}$ by varying the incident photon energy (IPE): ${ }^{40-42} 1.7 \mathrm{~nm}$ for $\mathrm{O}$ $1 \mathrm{~s}$ and $\mathrm{B}$ 1s photoelectrons (IPE 1050 and $725 \mathrm{eV}$, respectively); 1.1 and $2.1 \mathrm{~nm}$ for Co $2 \mathrm{p}_{3 / 2}$ photoelectrons (IPE 1050 and $1500 \mathrm{eV}$, respectively). Under IPE $1500 \mathrm{eV}$, the Co $2 \mathrm{p}_{3 / 2}$ region shows a peak at $778.4 \mathrm{eV}$ attributed to $\mathrm{CoB}^{43}$ and accompanied by a broad signal between 776 and $785 \mathrm{eV}$ characteristic of cobalt(II). ${ }^{44}$ The $\mathrm{O} 1 \mathrm{~s}$ contribution at $532.0 \mathrm{eV}$ is consistent with oxidized cobalt species, confirming the oxygen environment surrounding cobalt(II). The $\mathrm{O}$ 1s contribution at 533.0 $\mathrm{eV}$ corresponds to oxygen species linked to boron in agreement with the $\mathrm{B} 1 \mathrm{~s}$ contribution at $193.0 \mathrm{eV},{ }^{45}$ attributed to partially oxidized boron(II). The two other B $1 \mathrm{~s}$ contributions at 189.2 and $187.9 \mathrm{eV}$ correspond to elemental boron $\left(\mathrm{B}^{0}\right)$ and $\mathrm{CoB},{ }^{43}$ respectively. The high binding energy $(\mathrm{BE})$ for $\mathrm{B}^{0}$ compared to the reported values $^{22,45}$ is due to the nanostructure that yields charge effects. ${ }^{46} \mathrm{CoB}$ is detected in

the $\mathrm{B} 1 \mathrm{~s}$ region but also in the Co $2 \mathrm{p}_{3 / 2}$ region for a photon energy of $1500 \mathrm{eV}$. At a lower photon energy of $1050 \mathrm{eV}$ probing a thinner layer of ca. $1.1 \mathrm{~nm}$, cobalt(II) is the only species detected in the Co $2 \mathrm{p}_{3 / 2}$ region, with peaks more resolved than those at a photon energy of $1500 \mathrm{eV}: 779.3$ $\mathrm{eV}$ and a broader satellite at $782.5 \mathrm{eV}$ (Figure 2). ${ }^{44}$ 

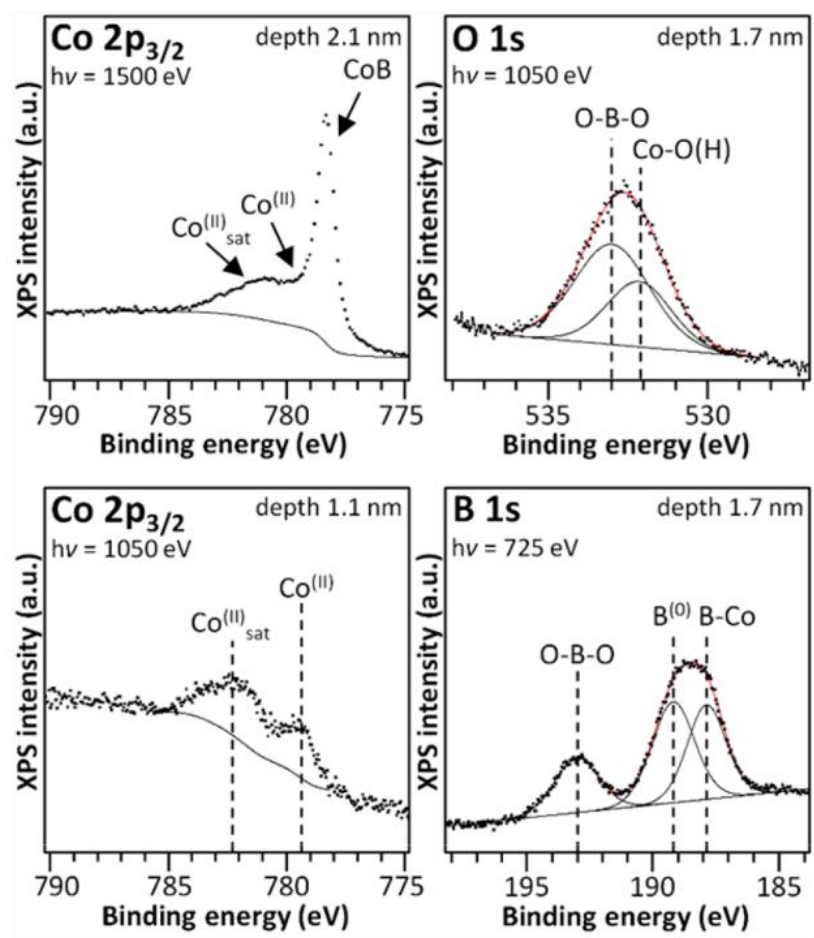

Figure 2. UHV-XPS spectra of the CoB nanocomposite in the Co $2 \mathrm{p} 3 / 2, \mathrm{O} 1 \mathrm{~s}$, and $\mathrm{B} 1 \mathrm{~s}$ regions in the initial state. hv = photon energy. The approximate depths of analysis are also given.

These XPS data provide strong support to XRD and STEM-HAADF analyses, showing that molten-salt-derived $\mathrm{CoB}$ is a nanocomposite made of $\mathrm{CoB}$ nanocrystals buried below a ca. 2-nm-thick amorphous layer, composed of partially oxidized amorphous boron $\left(\mathrm{B}^{0}\right.$ and $\mathrm{BO}_{2}$ species) and cobalt oxide and/or (oxyhydr)oxide inclusions (scheme in Figure 1).

Because the synthesis was performed in oxygen-free conditions, the oxidized boron and cobalt(II) species in the amorphous layer originate from exposure of the material to water during the washing step and air during storage. Interestingly, the cobalt(II) species may be interesting precursors to cobalt $(0)$ catalysts, especially for carbon monoxide $(\mathrm{CO})$ or $\mathrm{CO}_{2}$ methanation, like cobalt oxides. ${ }^{47}$ We thus explore in the following parts how a catalyst activation procedure, namely, reduction under hydrogen gas, impacts the nanostructure and local structure of the material. Then, as an example, we examine how a typical gas reagent mixture used for methanation [dihydrogen $\left(\mathrm{H}_{2}\right) / \mathrm{CO}_{2}$ ] can impact the activated material.

Both morphological and compositional evolutions were characterized using (i) environmental STEM with Zcontrast HAADF imaging, (ii) XPS under UHV and NAP conditions, which is sensitive only to modifications of the superficial layer (1-2 nm), and (iii) NEXAFS for a complementary spectroscopic characterization to a depth of approximately $10 \mathrm{~nm}$, i.e., comprising the $\mathrm{CoB}$ nanocrystals. Although there is a pressure gap between environmental TEM (1 bar) and NAP-XPS/NEXAFS (a few millibars), in the latter case, the material surface is fully saturated with adsorbates, thus providing relevant information on the actual state under higher pressure. ${ }^{48-51}$ Morphology Evolution of Nanoscaled Cobalt Boride under $\mathrm{H}_{2}$. STEM (Figure 3, left) and STEM-HAADF (Figure 3, right) images of the nanocomposite powder were recorded under environmental conditions.

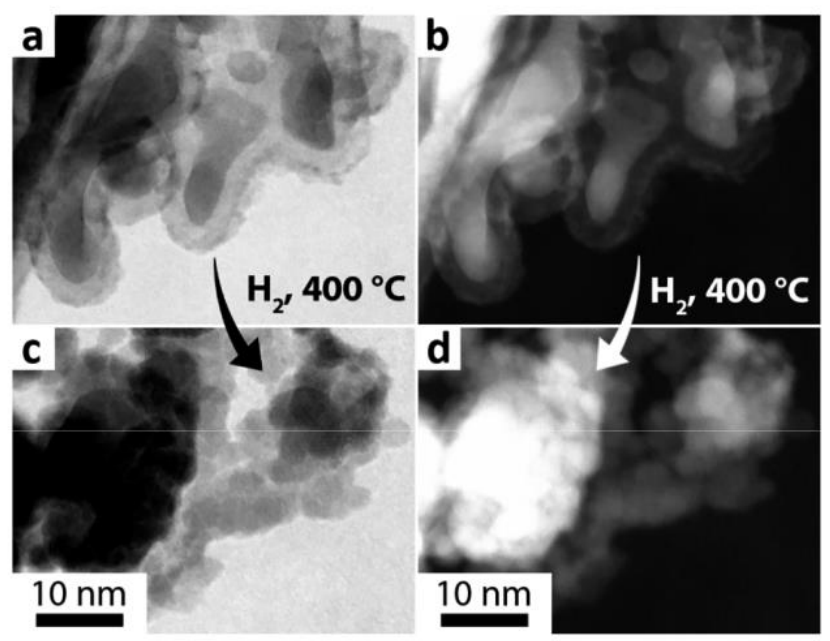

Figure 3. In situ STEM (left) and STEM-HAADF (right) images of the nanocomposite under different conditions: ( $a$ and $b$ ) under 0.3 bar of argon at $150{ }^{\circ} \mathrm{C}$; (c and d) under 0.9 bar of $\mathrm{H}_{2}$ at 400 ${ }^{\circ} \mathrm{C}$. The four micrographs are taken from the same region with an identical scale.

Under 0.3 bar of argon at $150{ }^{\circ} \mathrm{C}$ (Figure 3a,b), the morphological characteristics of the powder are similar to those of the pristine sample (Figure 1): CoB nanoparticles are surrounded by the amorphous layer containing cobaltrich inclusions. The same region is observed under reducing conditions (Figure 3c,d). Upon exposure to 0.9 bar of $\mathrm{H}_{2}$ at $400{ }^{\circ} \mathrm{C}$, core-shell particles reorganize into nanoparticles with homogeneous contrast, thus demonstrating strong morphological reconstruction of the initial crystalline particles (Figure S1), with fragmentation into smaller nano-particles. Chemical and structural evolutions accompanying these morphological changes under reactive gases were then investigated using XPS.

Surface Reactivity of Nanoscaled Cobalt Boride under Hydrogen. XPS under UHV conditions was performed on the $\mathrm{CoB}$ powder after exposure to a static atmosphere of 1 bar of pure $\mathrm{H}_{2}$ at $400{ }^{\circ} \mathrm{C}$ (Figure 4). The spectra in the Co $2 \mathrm{p}_{3 / 2}, \mathrm{O} 1 \mathrm{~s}$, and $\mathrm{B} 1 \mathrm{~s}$ regions were recorded with photon energies of 1050,725 , and $725 \mathrm{eV}$, respectively, corresponding to approximate depths of analysis of $1.1,0.9$, and $1.7 \mathrm{~nm}$. The Co $2 \mathrm{p}_{3 / 2}$ region shows one peak at $\sim 779.0 \mathrm{eV}$ corresponding to reduced cobalt, in accordance with the absence of $(\mathrm{H}) \mathrm{O}-\mathrm{Co}$ species in the $\mathrm{O}$ $1 \mathrm{~s}$ region. ${ }^{52}$ One single peak is detected in the $\mathrm{B} 1 \mathrm{~s}$ region at $195.4 \mathrm{eV}$. Similarly, in the O 1s region, one single peak is detected at $535.0 \mathrm{eV}$. Both signals correspond to fully oxidized boron. Compared to the usual BEs assigned to oxidized boron in previous literature data, they are shifted by $1.8 \mathrm{eV}$ to higher BEs. ${ }^{53}$ This discrepancy may originate from charge effects due to the nanostructure. Compared to the initial material in the $\mathrm{B} 1 \mathrm{~s}$ region, no $\mathrm{B}^{0}$ or $\mathrm{B}^{\mathrm{II}}$ is observed after $\mathrm{H}_{2}$ treatment.

Surface Reactivity of Nanoscaled Cobalt Boride under a Mixture of $\mathrm{H}_{2}$ and $\mathrm{CO}_{2}$. The nanomaterial treated under 1 bar of $\mathrm{H}_{2}$ at $400{ }^{\circ} \mathrm{C}$ and then analyzed by XPS under UHV conditions was exposed to a $\mathrm{H}_{2} / \mathrm{CO}_{2}$ gas mixture (4:1 volume ratio) at $400{ }^{\circ} \mathrm{C}$ during analysis. To enable NAP-XPS acquisition (Figure 4), the pressure in the chamber was kept at 2 mbar. Boron remains fully oxidized, as shown by the B $1 \mathrm{~s}$ and $\mathrm{O} 1 \mathrm{~s}$ contributions at 195.4 and at $534.8 \mathrm{eV}$, respectively. The absence of a peak at lower BEs in the $\mathrm{B} 1 \mathrm{~s}$ region indicates that neither $\mathrm{CoB}$ nor elemental and partially oxidized boron is present on the surface of the material (depth of analysis of $1.7 \mathrm{~nm}$ ). In the $\mathrm{O} 1 \mathrm{~s}$ region, 

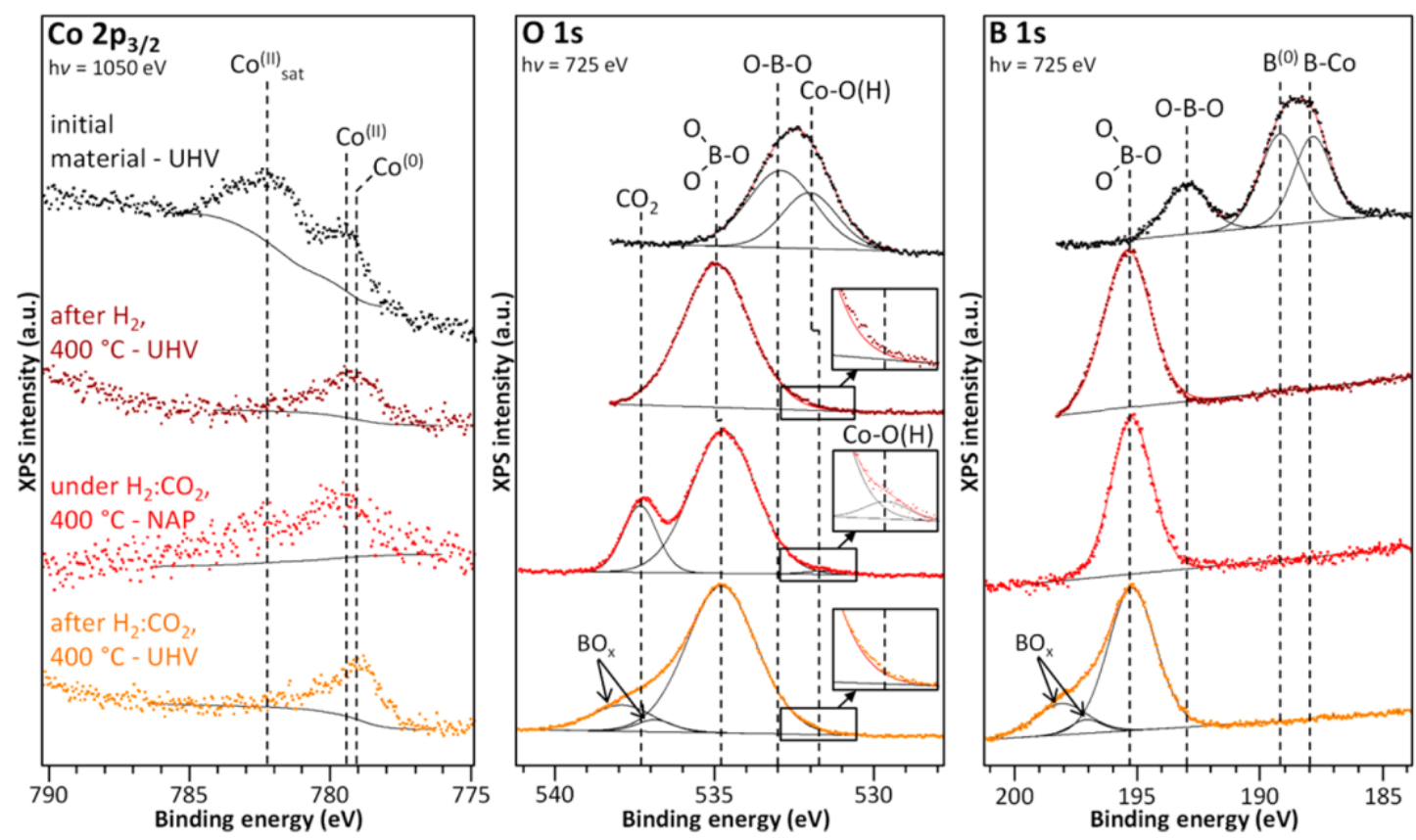

Figure 4. XPS spectra in the Co 2p3/2, O 1s, and B 1s regions of the CoB nanocomposite. From top to bottom: initial state under UHV; after exposure to 1 bar of $\mathrm{H}_{2}$ at $400{ }^{\circ} \mathrm{C}$ under $\mathrm{UHV}$; near-ambient-pressure conditions of $2 \mathrm{mbar}$ of $\mathrm{H}_{2} / \mathrm{CO}_{2}\left(4: 1\right.$ volume ratio) at $400{ }^{\circ} \mathrm{C}$; under $\mathrm{UHV}$ at $\mathrm{RT}$ after exposure to $\mathrm{H}_{2} / \mathrm{CO}_{2}\left(4: 1\right.$ volume ratio) at $400{ }^{\circ} \mathrm{C}$. hv $=$ photon energy.

the contribution at $537.4 \mathrm{eV}$ corresponds to gas-phase $\mathrm{CO}_{2}$. The shoulder of weak intensity at $532.0 \mathrm{eV}$ is ascribed to ( $\mathrm{H}) \mathrm{O}-\mathrm{Co}$ species (inset). In the Co $2 \mathrm{p}_{3 / 2}$ region, the broad satellite of oxidized cobalt is detected between 781 and 785 $\mathrm{eV}$, despite a poor signal-to-noise ratio due to the gas phase absorbing most of the emitted photoelectrons. Oxidized cobalt species thus form on the surface of the material when exposed to $\mathrm{H}_{2} / \mathrm{CO}_{2}$ at $400{ }^{\circ} \mathrm{C}$.

Back to RT and under UHV conditions (Figure 4), the signal in the Co $2 \mathrm{p}_{3 / 2}$ region shows the exclusive presence of metallic cobalt, while the shoulder at $532.0 \mathrm{eV}$ in the $\mathrm{O}$ 1s region disappears. Thus, the $(\mathrm{H}) \mathrm{O}-\mathrm{Co}$ species formed under NAP conditions are not stable under UHV conditions, and fully reduced cobalt species are restored, as observed after exposure to 1 atm of pure $\mathrm{H}_{2}$ at $400{ }^{\circ} \mathrm{C}$ (Figure 4). Note that two additional species (" $\mathrm{BO}_{\mathrm{x}}$ " in Figure 4) are detected. They are attributed to UHV-specific species and not representative of the material exposed to environmental conditions (discussion in the Supporting Information and Figure S2). All in all, zerovalent cobalt species are formed on the surface of the material initially composed of partially oxidized boron and $\mathrm{Co}^{\mathrm{II}}$ species. The contribution of deeper $\mathrm{CoB}$ in the $\mathrm{B}$ 1s region also disappears, but the changes of the monoboride core cannot be fully assessed using XPS. Indeed, XPS is only able to probe the first 1-2 $\mathrm{nm}$ beneath the surface. Hence, to probe the core of the material, especially the $\mathrm{CoB}$ nanoparticles buried under the superficial layer, we have performed NEXAFS on the same synchrotron beamline and the same materials as XPS measurements, also in NAP conditions. The total electron yield mode of NEXAFS was used to provide a depth of analysis of ca. $10 \mathrm{~nm}, 1$ order of magnitude deeper than that of XPS. ${ }^{54,55}$

Core Reactivity of Nanoscaled Cobalt Boride under $\mathrm{H}_{2}$ and $\mathbf{a} \mathrm{H}_{2} / \mathrm{CO}_{2}$ Mixture. NEXAFS spectra have been recorded to probe both crystalline nanoparticles and the amorphous component (analysis depth $\sim 10 \mathrm{~nm}$ ) at the Co Ledge, O K-edge, and B K-edge (Figure 5). The spectra for the initial state show contributions of $\mathrm{CoB}$, oxidized and nonoxidized (broad signal) of amorphous boron, and oxidized cobalt inclusions. Hence, NEXAFS confirms the conclusions obtained from XRD, TEM, and XPS: the initial material is constituted of $\mathrm{CoB}$ nanocrystals embedded in a 2-nm-thick amorphous layer, containing cobalt(II) in the form of oxides or (oxyhydr)oxides (scheme in Figure 1), dispersed in partially oxidized boron, with $\mathrm{BO}_{2}, \mathrm{BO}_{3}$, and $\mathrm{B}^{0}$ species. Between the initial state and the sample exposed to $\mathrm{H}_{2}$ at $400{ }^{\circ} \mathrm{C}$, the contributions of oxidized cobalt ${ }^{56}$ and elemental boron ${ }^{55}$ have disappeared, in agreement with UHV-XPS. NEXAFS thus confirms that the whole $\mathrm{CoB}$ core is converted into oxidized boron and metallic cobalt after exposure to the reducing atmosphere. NEXAFS spectra of the sample under $\mathrm{H}_{2} / \mathrm{CO}_{2}$ (NAP conditions) at $400{ }^{\circ} \mathrm{C}$ are also displayed. Although poorer signal-to-noise ratios are obtained, they are similar to those in the spectra after the reducing treatment. This indicates that no further change happens in the core of the material upon exposure to the $\mathrm{H}_{2} / \mathrm{CO}_{2}$ mixture, in agreement with XPS.

In brief, combined TEM, XPS, and NEXAFS studies demonstrate that the oxidized cobalt inclusions in the superficial layer, as well as the $\mathrm{CoB}$ nanoparticles, are converted into metallic cobalt nanoparticles during a $\mathrm{H}_{2}$ pretreatment, while boron is further oxidized by surrounding oxygen species initially bound to cobalt and possibly adsorbed water molecules. After the reducing treatment, the compositional homogeneity between the initial core and superficial layer observed by XPS and NEXAFS is in accordance with the TEM observations: core-shell nanoparticles turning to homogeneously contrasted ones.

Reactivity of Nanoscaled Nickel Boride under Hydrogen and a Mixture of $\mathrm{H}_{2}$ and Dioxygen $\left(\mathrm{O}_{2}\right)$. To assess the generality of the structural modifications evidenced on $\mathrm{CoB}$ upon exposure to a reactive gas atmosphere, $\mathrm{NiB}$ was investigated. The nanoparticles were synthesized using the 

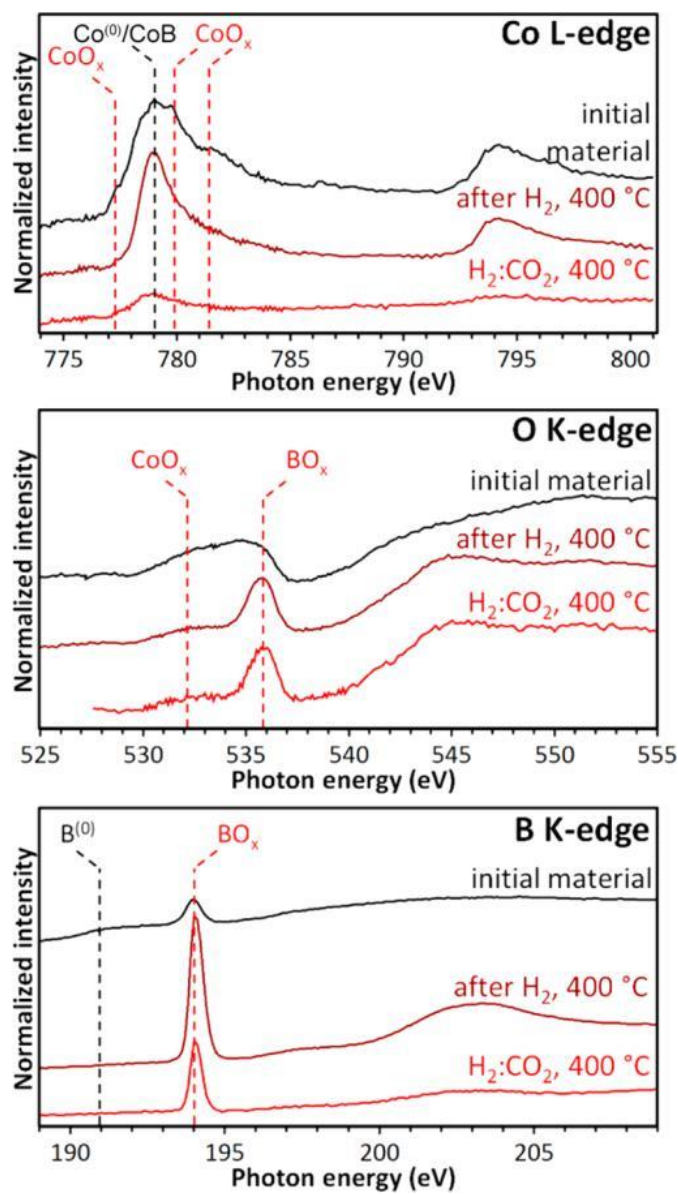

Figure 5. NEXAFS spectra at the Co L-edge, O K-edge, and B K-edge. From top to bottom: the initial $\mathrm{CoB}$ nanocomposite under UHV; after exposure to 1 bar of $\mathrm{H}_{2}$ at $400{ }^{\circ} \mathrm{C}$ under UHV; near-ambient-pressure conditions with 2 mbar of $\mathrm{H}_{2} / \mathrm{CO}_{2}\left(4: 1\right.$ volume ratio) at $400{ }^{\circ} \mathrm{C}$.

same inorganic molten salt route. The $\mathrm{NiB}$ nanocomposite is described in detail elsewhere. ${ }^{6}$ This material is made of $\mathrm{NiB}$ nanocrystals surrounded by an amorphous layer. The XRD pattern of the as-obtained powder highlights the presence of $\mathrm{NiB}$ crystallites with apparent sizes of $9 \pm 2$ $\mathrm{nm}^{6}$ together with traces of $\mathrm{Ni}_{4} \mathrm{~B}_{3}$ (Figure 6b, top). In contrast to $\mathrm{CoB}$, it has been shown recently by TEM that no nickel atom resides in the superficial amorphous layer ${ }^{6}$ and that all the nickel atoms are involved in $\mathrm{NiB}$. The $\mathrm{NiB}$ nanoparticles are exposed consecutively to reducing and oxidizing conditions at $1 \mathrm{~atm}$. The different steps are schematized in Figure 6a. Chromatog-raphy analysis of the exhaust gas does not show any $\mathrm{H}_{2}$ consumption during all reducing steps (not shown). Oxygen depletion from 320 to $420{ }^{\circ} \mathrm{C}$ during the first oxidation step (Figure 6c) indicates oxidation of the nanocomposite. No further $\mathrm{O}_{2}$ consumption is observed in the subsequent oxidizing steps (Figure 6d), despite the intermediate reducing treatments. The first oxidation process is thus irreversible. After subsequent cycles, the NiB black powder turns into a black monolith and a white powder deposits onto the reactor walls. The XRD pattern of the monolith highlights the presence of metallic nickel and traces of $\mathrm{Ni}_{3} \mathrm{~B}$ instead of the parent $\mathrm{NiB}$ and $\mathrm{Ni}_{4} \mathrm{~B}_{3}$ (minor amount) material (Figure 6b, bottom). The resulting nickel particles exhibit a crystallite size of ca. $30 \mathrm{~nm}$. Segregation of nickel and boron can then be correlated to boron oxidation during the first oxidation treatment. The $\mathrm{O} / \mathrm{B}$ molar ratio is 1.5 according to $\mathrm{O}_{2}$ consumption in the first oxidation step, in good agreement with the expected stoichiometry of $\mathrm{B}_{2} \mathrm{O}_{3}$. The white powder deposited on the reactor walls is therefore $\mathrm{B}_{2} \mathrm{O}_{3}$, which is known to melt at $450{ }^{\circ} \mathrm{C}$ and shows high volatility in this temperature range. ${ }^{57}$

Catalysis of $\mathrm{CO}_{2}$ Methanation over CoB-Derived Cobalt Nanoparticles. In situ studies shown above demonstrate that exposure to $\mathrm{H}_{2}$ at $400{ }^{\circ} \mathrm{C}$ triggers phase segregation of $\mathrm{CoB}$ into oxidized boron and cobalt $(0)$, a typical catalyst of carbon (di)oxide methanation. Hence, we assessed the catalytic activity of our $\mathrm{CoB}$ material toward $\mathrm{CO}_{2}$ methanation. The material was deposited on $\mathrm{TiO}_{2}-\mathrm{P} 25$ Degussa (mixture of $20-50 \mathrm{~nm}$ rutile/anatase titania nanoparticles in a 20/80 mass ratio; specific surface area of about $60 \mathrm{~m}^{2} \mathrm{~g}^{-1}$ ) as a support already used for $\mathrm{CO}_{2}$ methanation. ${ }^{58,59}$ The supported material (10 wt \%) was treated in situ under $\mathrm{H}_{2}(1 \mathrm{~atm})$ at $400{ }^{\circ} \mathrm{C}$ for $2 \mathrm{~h}$ and then exposed to a $\mathrm{H}_{2} / \mathrm{CO}_{2} /$ helium mixture with a 4:1:5 volume ratio at $1 \mathrm{~atm}$. The gas outlet was analyzed by gas-phase chromatography. No species other than methane $\left(\mathrm{CH}_{4}\right)$ and a)

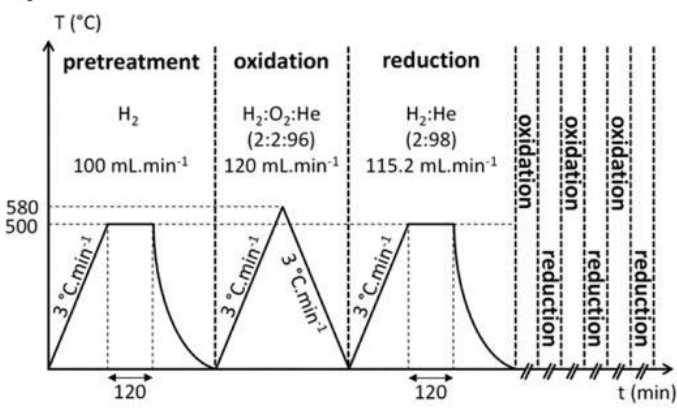

b)

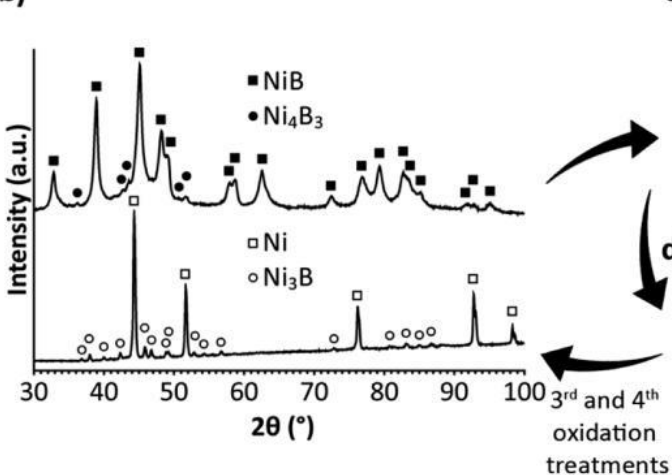

c)

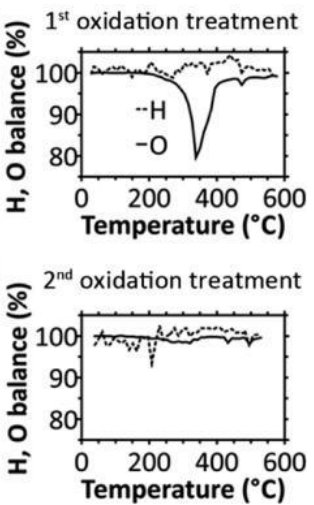

Figure 6. Destabilization of NiB nanoparticles during reduction and oxidation treatments. (a) Consecutive treatments under gases. The oxidation- reduction treatment was repeated four times. (b) XRD patterns of a sample composed of NiB nanoparticles (top) synthesized in inorganic molten salts at $750{ }^{\circ} \mathrm{C}$ for $1.5 \mathrm{~h}$ and the sample after the reducing-oxidizing treatments (bottom). (c and d) Elemental hydrogen and oxygen balances during the two first consecutive oxidizing heat treatments of $\mathrm{NiB}$ nanoparticles: $\mathrm{H}_{2} / \mathrm{O}_{2} / \mathrm{helium}$ mixture (2:2:96 volume ratio) to $580{ }^{\circ} \mathrm{C}$ at $3{ }^{\circ} \mathrm{C} \mathrm{min}^{-1}$. Two oxidizing treatments are separated by exposure to $\mathrm{H}_{2} /$ helium $\left(2: 98\right.$ volume ratio) at $500{ }^{\circ} \mathrm{C}$ for $2 \mathrm{~h}$, not showing any consumption of hydrogen (not shown). Elemental balances during the third and fourth oxidation treatments are similar to that shown in part $d$. 


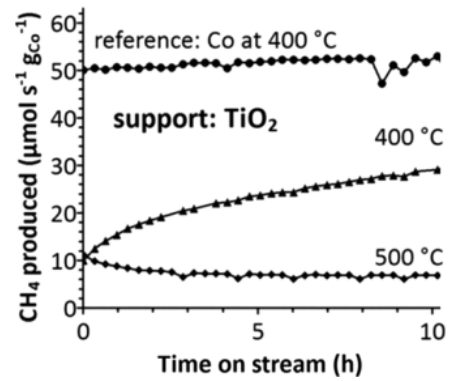

Figure 7. $\mathrm{CH}_{4}$ production rate as a function of the time on stream for $\mathrm{TiO}_{2}$-supported $\mathrm{CoB}$ at 400 and $500{ }^{\circ} \mathrm{C}$. The behavior of a $\mathrm{Co} / \mathrm{TiO}_{2}$ reference sample is also shown for comparison. Inner gas mixture: $\mathrm{H}_{2} / \mathrm{CO}_{2} /$ helium (4:1:5 volume ratio), $1 \mathrm{~atm}, 20 \mathrm{~mL}$ $\min ^{-1}$. Pretreatment: $\mathrm{H}_{2}, 1 \mathrm{~atm}, 30 \mathrm{~mL} \mathrm{~min}^{-1}$ at $400{ }^{\circ} \mathrm{C}$ for $2 \mathrm{~h}$.

production rate measured after $20 \mathrm{~min}$ on stream strongly depends on the temperature (Figure S3). It is maximized between 400 and $500{ }^{\circ} \mathrm{C}$. Figure 7 shows the $\mathrm{CH}_{4}$ production rate as a function of the time on stream at 400 and $500{ }^{\circ} \mathrm{C}$. Deactivation occurs at $500{ }^{\circ} \mathrm{C}$, but the behavior at $400^{\circ} \mathrm{C}$ is drastically different: the $\mathrm{CH}_{4}$ production rate continuously increases during the whole experiment. Increases of 2- and 3-fold are observed after 2 and $10 \mathrm{~h}$ on stream, respectively. Note that, after $10 \mathrm{~h}$ on stream, the production rate of $\mathrm{CH}_{4}$ has not yet reached a steady state, but it is still increasing over ca. $30 \mathrm{~mol} \mathrm{~s}^{-1}$ $\mathrm{g}_{\mathrm{Co}}{ }^{-1}$. In comparison, a reference $\mathrm{Co} / \mathrm{TiO}_{2}-\mathrm{P} 25$ sample with the same cobalt content, formed by wet impregnation of $\mathrm{Co}_{3} \mathrm{O}_{4}$ supported on titania, ${ }^{60}$ shows a constant $\mathrm{CH}_{4}$ production rate of $50 \mathrm{~mol} \mathrm{~s}^{-1} \mathrm{~g}_{\mathrm{Co}}{ }^{-1}$. Activation of the $\mathrm{CoB}$ sample with time on stream at $400{ }^{\circ} \mathrm{C}$ therefore indicates that significant modifications of the catalyst occur, with the activity trend toward the behavior of cobalt, in accordance with the structural evolutions described in the previous sections. To confirm such changes, $\mathrm{TiO}_{2}$-supported $\mathrm{CoB}$ materials have been extracted after each step of the catalysis test (Figure S4). Indeed, powder XRD patterns show phase segregation from $\mathrm{CoB}$ to cubic cobalt. The generality of the decomposition process has been confirmed by using silica as an alternative support (Figures S5 and S6).

Instability of Metal Borides Exposed to Reactive Atmospheres. The experiments reported above clearly demonstrate both chemical and morphological changes of the CoB-based nanocomposite due to exposure to $\mathrm{H}_{2}$. These changes are schematized in Figure 8. In the superficial amorphous layer, the formation of cobalt nanoparticles occurs through borothermal reduction: reduction of cobalt(II) oxides

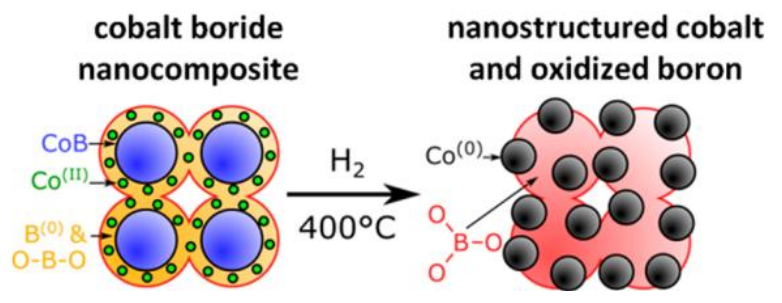

Figure 8. Chemical and morphological modifications of the $\mathrm{CoB}$ nanocomposite upon exposure to $\mathrm{H}_{2}$. and/or (oxyhydr)oxides by the initially present elemental boron and partially oxidized boron species.

In the core, elemental segregation leads to metallic cobalt, while boron is oxidized either in boron oxide or in boric acid. Heat treatments of amorphous cobalt-boron thin films under various atmospheres were shown by Patel et al. to lead to metallic cobalt only under pure $\mathrm{O}_{2} \cdot{ }^{61}$ In our case, treatment under $\mathrm{H}_{2}$ diluted in argon $(5$ vol \%) does not destabilize $\mathrm{CoB}$ up to $800{ }^{\circ} \mathrm{C}$ (Figure S7). Hence, temperature is not the only parameter explaining decomposition of $\mathrm{CoB}$ nanocrystals, but the atmosphere is important: strong reducing conditions are also required to form cobalt nanoparticles. On the other side, $\mathrm{NiB}$ undergoes decomposition when exposed to oxidizing conditions, through the formation of boron oxide. Metallic nickel is the major phase obtained and boron is irreversibly oxidized, as was already seen for CoB. ${ }^{19,61}$ Our original observation is the generality of the decomposition of metal boride nanomaterials previously handled under air and moisture, when they are exposed to gas-phase treatment, in strongly oxidizing and reducing conditions.

In the catalytic hydrolysis of $\mathrm{NaBH}_{4}$ by cobalt-boron materials, the nature of the active site has been extensively discussed, ${ }^{21,22,27,36,61}$ whether it is composed of cobalt only, cobalt and boron in an amorphous alloy, or one of the known crystalline cobalt-boron phases. Besides, boron $(0.5$ wt \%) is known to act as a promoter of cobalt catalysts of the Fischer- Tropsch process by hindering coking. ${ }^{62}$ Our results provide evidence for the instability of crystalline cobalt boride under a $\mathrm{H}_{2}$ atmosphere and at relatively low temperatures $\left(400{ }^{\circ} \mathrm{C}\right)$ compared to the temperature of synthesis $\left(750{ }^{\circ} \mathrm{C}\right)$, yielding metallic cobalt as the only cobalt species. Our results put also into perspective that the intrinsic activity of cobalt-boron materials in the hydrolysis of $\mathrm{NaBH}_{4}$ may result from its segregation to metallic cobalt nanoparticles. Indeed, Arzac et al. ${ }^{27}$ highlighted the presence of cobalt particles through ex situ characterization in such systems. In the present study, NAP-XPS experiments unravel the true nature of the active surface composed of elemental cobalt, $\mathrm{Co}-\mathrm{O}(\mathrm{H})$ in small proportions, and oxidized boron. Similar in situ studies applied to amorphous cobalt boride should provide useful information on the real active site in these systems, for which no consensus has been reached so far. ${ }^{22}$ In the mechanism of $\mathrm{CO}_{2}$ methanation, the detection of $\mathrm{Co}-\mathrm{O}(\mathrm{H})$ during in situ NAP-XPS is in favor of a steady state comprising partially oxidized cobalt. This is in accordance with previous works describing the dissociation of $\mathrm{CO}_{2}$ by cobalt through the formation of $\mathrm{CoO} .{ }^{63}$ Under the catalytic conditions of methanation, the surface concentration of oxidized cobalt might be even higher than that during NAP-XPS experiments $(2 \mathrm{mbar})$ because the $\mathrm{CO}_{2}$ partial pressure is much higher (0.1 bar).

Catalytic Activity of Metal Cobalt Nanoparticles Surrounded by Oxidized Boron. Cobalt nanoparticles obtained from $\mathrm{CoB}$ decomposition during the $\mathrm{H}_{2}$ pretreatment are the actual active species catalyzing $\mathrm{CO}_{2}$ methanation. After $\mathrm{H}_{2}$ pretreatment, the size of the cobalt nanoparticles varies from 15 to $20 \mathrm{~nm}$ when supported on silicon dioxide $\left(\mathrm{SiO}_{2}\right)$, according to the XRD data (Figure S6), in agreement with the particle sizes reported for cobalt nanoparticles supported on $\mathrm{SiO}_{2}$ and titanium dioxide $\left(\mathrm{TiO}_{2}\right) .{ }^{64}$ Interestingly, NAP-XPS in the B $1 \mathrm{~s}$ region during exposure to $\mathrm{H}_{2} / \mathrm{CO}_{2}$ indicates no specific species involving boron in the steady state.

The nature of the support onto which $\mathrm{CoB}$ was deposited has a drastic influence on the $\mathrm{CO}_{2}$ methanation reaction. 
$\mathrm{CoB} / \mathrm{TiO}_{2}$ indeed shows a $\mathrm{CH}_{4}$ production rate up to 5 times higher than that found on $\mathrm{CoB} / \mathrm{SiO}_{2}$ at a reaction temperature of $400{ }^{\circ} \mathrm{C}$. The $\mathrm{CH}_{4}$ production rates for the cobalt reference and the $\mathrm{CoB}$-based/TiO $/ \mathrm{T}_{2}$ samples are of the same order of magnitude after almost $14 \mathrm{~h}$ on stream at 400 ${ }^{\circ} \mathrm{C}$, in agreement with the formation of dispersed cobalt nanoparticles from segregation in the $\mathrm{CoB}$ precursor upon in situ exposure to $\mathrm{H}_{2}$. The continuous activity increase with the time on stream for $\mathrm{TiO}_{2}$-supported $\mathrm{CoB}$ at $400{ }^{\circ} \mathrm{C}$ should be related to reorganization of boron (hydr)oxide, leading to a better exposure of cobalt nanoparticles. Such a rearrangement could facilitate interactions between cobalt particles and the $\mathrm{TiO}_{2}$ support. For cobalt-based catalytic materials, Riva et al. showed that $\mathrm{TiO}_{2}$ favored the dispersion of cobalt nanoparticles during the reduction treatment thanks to metal-support interactions, while the cobalt particles sinter on $\mathrm{SiO}_{2}$ due to the lack of significant interactions. ${ }^{60}$ In the present case, $\mathrm{TiO}_{2}$ might also favor dispersion of cobalt nanoparticles after elemental segregation occurred.

\section{CONCLUSION}

To conclude, we have exploited in situ ensemble and local analyses to unravel the formation of metal nanoparticles upon exposure of nanocrystalline $\mathrm{CoB}$ to a reducing gas phase. Similarly, nickel borides decompose under oxidizing conditions. Such a decomposition at relatively low temperatures $\left(400{ }^{\circ} \mathrm{C}\right)$ under a reactive atmosphere appears as a general process for metal borides obtained from the molten salt synthesis. In this process, boron is fully and irreversibly oxidized by oxygen species from the gas phase or from exposure to water and air prior to thermal treatment. Accordingly, our study points out strong morphological, chemical, and structural evolutions, which stress the special care that must be taken to attribute the measured properties, especially catalytic properties, to these crystalline materials. From these observations, the general instability of metal boride nanomaterials at relatively low temperatures $\left(400{ }^{\circ} \mathrm{C}\right)$ under reactive atmospheres is questioned. By exploring with this study the stability ranges of boride nanomaterials, we delineate their acceptable ranges of study and application and we uncover the possible use of reducing atmospheres to exploit decomposition in boron compounds to yield complex materials. ${ }^{65}$

\section{EXPERIMENTAL SECTION}

Synthesis. The reaction medium was prepared in an argon-filled glovebox (M-Braun). A total of $4 \mathrm{mmol}$ of $\mathrm{NaBH}_{4}$ (min 98\%, Alfa Aesar) and $2 \mathrm{mmol}$ of anhydrous $\mathrm{CoCl}_{2}(99.99 \%$, Alfa Aesar) were mixed with $5 \mathrm{~g}$ of a vacuum-dried $\mathrm{LiCl} / \mathrm{KCl}$ mixture at the eutectic composition $(45 / 55 \mathrm{wt} \%)$. The powders were finely ground in a ballmill (Retsch MM400) for $2 \mathrm{~min}$ at $20 \mathrm{~Hz}$ and then transferred into a glassy-carbon crucible. The crucible was maintained in a quartz tube, which was connected to an argon ramp. The medium was heated in a vertical oven (Carbolite) from RT to $750{ }^{\circ} \mathrm{C}\left(10^{\circ} \mathrm{C} \min ^{-1}\right)$ and maintained at $750{ }^{\circ} \mathrm{C}$ for $1.5 \mathrm{~h}$. The medium was stirred with a glassy-carbon rod rotating at $100 \mathrm{rpm}$. After the apparatus cooled to RT, the frozen salt medium was washed with deionized water, the suspension was centrifuged for $15 \mathrm{~min}$ at $20 \mathrm{krpm}$ (Nalgene), and the powder was separated from the supernatant. This washing procedure was repeated three times. The black powder was finally evacuated at $40{ }^{\circ} \mathrm{C}$ overnight.
$\mathrm{H}_{2}$ Reduction and $\mathrm{H}_{2} / \mathrm{O}_{2}$ Oxidation Treatments. A total of $50.6 \mathrm{mg}$ of $\mathrm{NiB}$ powder (synthesis described in ref 6) was introduced into a continuous-flow quartz reactor. First, the powder was treated under $100 \mathrm{~mL} \mathrm{~min}^{-1}$ of $\mathrm{H}_{2}(1 \mathrm{~atm})$ for 2 $\mathrm{h}$ at $500{ }^{\circ} \mathrm{C}$. After cooling to RT, the sample was exposed four times to oxidation $\left(120 \mathrm{~mL} \mathrm{~min}{ }^{-1}\right.$ of a $\mathrm{H}_{2} / \mathrm{O}_{2} /$ helium mixture; volume ratio of 2:2:96; heating at $3{ }^{\circ} \mathrm{C} \mathrm{min}{ }^{-1}$ from RT to $\left.580{ }^{\circ} \mathrm{C}\right)$ and reduction treatments $\left(115.2 \mathrm{~mL} \mathrm{~min}^{-1}\right.$ of $\mathrm{a} \mathrm{H}_{2}$ /helium mixture, volume ratio of $2: 98,3{ }^{\circ} \mathrm{C} \mathrm{min}{ }^{-1}$ from RT to $500{ }^{\circ} \mathrm{C}$ and $2 \mathrm{~h}$ at $500{ }^{\circ} \mathrm{C}$ ). $\mathrm{H}_{2}, \mathrm{O}_{2}$, and $\mathrm{H}_{2} \mathrm{O}$ concentrations were measured using a $\mathrm{CP} 4900$ microchromatograph (Varian).

$\mathrm{CO}_{2}$ Methanation. Supported CoB Materials. A total of $40.0 \mathrm{mg}$ of the cobalt boride powder was dispersed in deionized water and added dropwise to $360.0 \mathrm{mg}$ of $\mathrm{TiO}_{2-}$ P25 (Degussa) or $\mathrm{SiO}_{2}$-Aerosil 200 (Degussa; $10 \mathrm{~nm}$ nanoparticles; specific surface area of $200 \mathrm{~m}^{2} \mathrm{~g}^{-1}$ ) suspended in deionized water during stirring. The resulting mixture was then sonicated in a USC100TH bath (VWR) for $5 \mathrm{~min}$ and stirred for $5 \mathrm{~min}$ three times. The dispersion was dried using a rotary evaporator (Büchi) at $60{ }^{\circ} \mathrm{C}$. The reference-supported cobalt material was obtained from $\mathrm{Co}_{3} \mathrm{O}_{4}$ supported on $\mathrm{TiO}_{2}$. This precursor was synthesized by the following procedure: $341.3 \mathrm{mg}$ of $\mathrm{Co}\left(\mathrm{NO}_{3}\right)_{2} \cdot 6 \mathrm{H}_{2} \mathrm{O}$ was dissolved in deionized water and added dropwise to $735.8 \mathrm{mg}$ of $\mathrm{TiO}_{2}-\mathrm{P} 25$ (Degussa) suspended in deionized water during stirring. The suspension was stirred for $48 \mathrm{~h}$ at $\mathrm{RT}$ and then dry-evaporated at $95^{\circ} \mathrm{C}$. The powder was then annealed at $500^{\circ} \mathrm{C}$ during $20 \mathrm{~h}$ in air.

Methanation Experiments. A total of $200 \mathrm{mg}$ of precatalyst with particle sizes between 100 and $315 \mu \mathrm{m}$ was loaded into a continuous-flow fixed-bed reactor and reduced in situ at $400{ }^{\circ} \mathrm{C}$ for $2 \mathrm{~h}$ under $30 \mathrm{~mL} \mathrm{~min}^{-1}$ of $\mathrm{H}_{2}$ (1 atm) prior to the catalytic reaction. The reaction was carried out at $1 \mathrm{~atm}$ from 200 to $500{ }^{\circ} \mathrm{C}$ under a reaction mixture composed of $\mathrm{CO}_{2} / \mathrm{H}_{2} /$ helium (1:4:5 volume ratio) at $20 \mathrm{~mL} \mathrm{~min}{ }^{-1}$. The exhaust gases were quantified using a gas chromatograph (Varian CP3800), equipped with Hayesep Q, Molsieve $5 \AA$, and CP-Sil-5CB columns. The reactants and products were detected with a flame ionization detector $\left(\mathrm{CH}_{4}\right)$ and a thermal conductivity detector $\left(\mathrm{CO}\right.$ and $\left.\mathrm{CO}_{2}\right)$. The exhaust gases were analyzed every 19 min with $\sim 1 \%$ (relative) accuracy for the $\mathrm{CH}_{4}$ production rate (moles of $\mathrm{CH}_{4}$ produced per gram of cobalt per second). All transfer lines were maintained at $110^{\circ} \mathrm{C}$ to avoid water condensation.

In Situ TEM. STEM-HAADF and environmental TEM were performed at the Institut de Physique et de Chimie de Strasbourg on a $200 \mathrm{kV}$ JEOL $2100 \mathrm{~F}$ instrument [METSA (Microscopie Electronique et Sonde Atomique) national network] equipped with a Cs probe corrector, allowing one to achieve spatial resolutions down to $0.11 \mathrm{~nm}$. For environmental TEM, the sample was exposed to a continuous $0.01 \mathrm{~mL} \mathrm{~min}^{-1}$ gas flow. The sample holder was an Atmosphere model from Protochips able to withstand pressures of up to $1 \mathrm{~atm}$ and temperatures of up to $1000{ }^{\circ} \mathrm{C}$ $\left( \pm 3{ }^{\circ} \mathrm{C}\right.$ and with high heating/cooling speeds of $50{ }^{\circ} \mathrm{C} \mathrm{s}^{-1}$ ) under gas flow. These severe conditions do not alter the microscope performances in terms of spatial and energy resolution. The main drawback of the environmental TEM is electron beam damage, which may impact the microstructural changes within the region of interest during the treatment. To overcome this, specimen exposure to the electron beam was minimized, by carrying out all preliminary alignments away from the areas examined during the tests.

XPS. Most XPS experiments were performed on the NAP-XPS end station (SPECS) on the TEMPO beamline of the Synchrotron SOLEIL (Gif sur Yvette Cedex, France). The hemispheric electron analyzer was a Phoibos 150 NAP apparatus (SPECS). 
The samples were prepared by the dip-coating technique using a dip-coater (SolGelWay). Nanoparticles suspended in ethanol $\left(30 \mathrm{mg} \mathrm{mL}^{-1}\right)$ were deposited on a silicon wafer coated with a 50-nm-thick gold layer. The XPS spectra were calibrated according to the $\mathrm{Au} 4 \mathrm{f}_{7 / 2}$ signal at $84.0 \mathrm{eV}$. Data analysis was performed on the CasaXPS software. Peaks were fitted using GL(30) component line shapes with

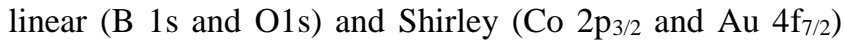
background types. The $\mathrm{BE}$ and full width at half-maximum (BE, eV; fwhm, eV) of the contributions

are as follows: (i) in the $\mathrm{B} 1 \mathrm{~s}$ region, $\mathrm{CoB}(187.9,1.8), \mathrm{B}^{0}$ (189.2, 2.0), $\mathrm{BO}_{2}(193.0,2.1), \mathrm{BO}_{3}(195.4,2.2)$, and the high-BE $\mathrm{BO}_{3}$ species $(197.1,1.5)$ and $(198.1,2.5)$; (ii) in the $\mathrm{O} 1 \mathrm{~s}$ region, $\mathrm{Co}^{-} \mathrm{O}(\mathrm{H})$

$(532.0,2.3), \mathrm{BO}_{2}(533.0,2.4), \mathrm{BO}_{3}$ (534.9, 2.4), $\mathrm{CO}_{2}$ $(537.4,1.3)$, and the high-BE $\mathrm{BO}_{3}$ species $(536.9,1.4)$ and $(537.9,2.3)$. The spectrum recorded at $1500 \mathrm{eV}$ was obtained on an Omicron Technology apparatus at the IMPC. It was equipped with a hemispheric analyzer (SPECS) and an aluminum cathode with an $\mathrm{Al} \mathrm{K \alpha}$ monochromator. In this case, the XPS spectrum was calibrated according to the $\mathrm{C} 1 \mathrm{~s}$ signal at $285.0 \mathrm{eV}$. The depth of XPS analysis in each region was evaluated by calculating the inelastic mean-free path of electrons extracted with a given kinetic energy from a given material. ${ }^{66}$ Because the superficial layer is mainly composed of boron and oxygen, it is approximated to boron oxide for the calculations (considering that only boron yields similar values).

NEXAFS. NEXAFS spectra were recorded on the TEMPO beamline at Synchrotron SOLEIL (see above) in the total electron yield mode. The studied energy windows were as follows: (i) B K-edge, 185-205 eV with $0.1 \mathrm{eV}$ steps and 205-220 eV with $0.2 \mathrm{eV}$ steps; (ii) O K-edge, 525-530 eV with $0.2 \mathrm{eV}$ steps, 530-540 eV with $0.1 \mathrm{eV}$ steps, and 540-555 eV with $0.2 \mathrm{eV}$ steps; (iii) Co L-edge, 770- $774 \mathrm{eV}$ with $0.2 \mathrm{eV}$ steps, 774-785 eV with $0.1 \mathrm{eV}$ steps, and 785-810 eV with $0.2 \mathrm{eV}$ steps.

\section{ASSOCIATED CONTENT}

The Supporting Information is available free of charge on the ACS Publications website at DOI: 10.1021/acs.inorgchem.7b01279.

Characterization methods and Figures S1-S7 (PDF)

\section{AUTHOR INFORMATION}

\section{Corresponding Author \\ *E-mail: david.portehault@upmc.fr. \\ ORCID}

Damien P. Debecker: 0000-0001-6500-2996

Cyril Thomas: 0000-0003-4224-6095

David Portehault: 0000-0003-4914-4913

Present Addresses

‡G.G.: Institut de Chimie de la Matierè Condenseéde Bordeaux-CNRS, 33607 Pessac Cedex, France.

IS.M.: Groupe de Physique des Materiaux, University of Rouen, CNRS, France.

\section{Notes}

The authors declare no competing financial interest.

\section{ACKNOWLEDGMENTS}

The authors acknowledge Patricia Beaunier from the Institut des Materiaux de Paris Centre for HRTEM and Domitille Giaume from the Institut de Recherche de Chimie Paris for ICP-OES. This work has been funded by the Ministere de l'Enseignement Superieur et de la Recherche. The experiments at the TEMPO beamline at Synchrotron SOLEIL have been funded by SOLEIL under the User Proposal 20140081. CNRS, Sorbonne Universites, UPMC, College de France, and the METSA network are acknowledged for financial support.

\section{REFERENCES}

(1) Terlan, B.; Levin, A.; Börrnert, F.; Simon, F.; Oschatz, M.; Schmidt, M.; Cardoso-Gil, R.; Lorenz, T.; Baburin, I.; Joswig, J.-O.; et al. Effect of Surface Properties on the Microstructure, Thermal and Colloidal Stability of $\mathrm{VB}_{2}$ Nanoparticles. Chem. Mater. 2015, 27, 5106-5115.

(2) Mattox, T. M.; Agrawal, A.; Milliron, D. J. Low Temperature Synthesis and Surface Plasmon Resonance of Colloidal Lanthanum Hexaboride ( $\mathrm{LaB}_{6}$ ) Nanocrystals. Chem. Mater. 2015, 27, 6620-6624.

(3) Rades, S.; Kornowski, A.; Weller, H.; Albert, B. WetChemical Synthesis of Nanoscale Iron Boride, XAFS Analysis and Crystallisation to $\alpha-\mathrm{FeB}$. ChemPhysChem 2011, 12, 1756-1760.

(4) Rades, S.; Kraemer, S.; Seshadri, R.; Albert, B. Size and Crystallinity Dependence of Magnetism in Nanoscale Iron Boride, $\alpha$-FeB. Chem. Mater. 2014, 26, 1549-1552.

(5) Portehault, D.; Devi, S.; Beaunier, P.; Gervais, C.; Giordano, C.; Sanchez, C.; Antonietti, M. A General Solution Route toward Metal Boride Nanocrystals. Angew. Chem., Int. Ed. 2011, 50, 3262-3265.

(6) Gouget, G.; Beaunier, P.; Portehault, D.; Sanchez, C. New Route toward Nanosized Crystalline Metal Borides with Tunable Stoichiom-etry and Variable Morphologies. Faraday Discuss. 2016, 191, 511-525.

(7) Carenco, S.; Portehault, D.; Boissiere, C.; Mezailles', N.; Sanchez, C. 25th Anniversary Article: Exploring Nanoscaled Matter from Speciation to Phase Diagrams: Metal Phosphide Nanoparticles as a Case of Study. Adv. Mater. 2014, 26, 371-390.

(8) Carenco, S.; Portehault, D.; Boissiere, C.; Mezailles', N.; Sanchez, C. Nanoscaled Metal Borides and Phosphides: Recent Developments and Perspectives. Chem. Rev. 2013, 113, 7981-8065.

(9) Nagamatsu, J.; Nakagawa, N.; Muranaka, T.; Zenitani, Y.; Akimitsu, J. Superconductivity at $39 \mathrm{~K}$ in Magnesium Diboride. Nature 2001, 410, 63-64.

(10) Mori, T. Novel Physical Properties of Rare Earth Higher Borides. J. Phys. Conf. Ser. 2009, 176, 12036.

(11) Albert, B.; Hillebrecht, H. Boron: Elementary Challenge for Experimenters and Theoreticians. Angew. Chem., Int. Ed. 2009, 48, 8640-8668.

(12)Levine, J. B.; Tolbert, S. H.; Kaner, R. B. Advancements in the Search for Superhard UltraIncompressible Metal Borides. Adv. Funct. Mater. 2009, 19, 3519-3533.

(13)Mohammadi, R.; Lech, A. T.; Xie, M.; Weaver, B. E.; Yeung, M. T.; Tolbert, S. H.; Kaner, R. B. Tungsten Tetraboride, an Inexpensive Superhard Material. Proc. Natl. Acad. Sci. U. S. A. 2011, 108, 10958-10962. 
(14) Lech, A. T.; Turner, C. L.; Mohammadi, R.; Tolbert, S. H.; Kaner, R. B. Structure of Superhard Tungsten Tetraboride: A Missing Link between $\mathrm{MB}_{2}$ and $\mathrm{MB}_{12}$ Higher Borides. Proc. Natl. Acad. Sci. U. S. A. 2015, 112, 3223-3228.

(15)Mattox, T. M.; Chockkalingam, S.; Roh, I.; Urban, J. J. Evolution of Vibrational Properties in Lanthanum Hexaboride Nanocrystals. J. Phys. Chem. C 2016, 120, 5188-5195.

(16) Mohammadi, R.; Turner, C. L.; Xie, M.; Yeung, M. T.; Lech, A. T.; Tolbert, S. H.; Kaner, R. B. Enhancing the Hardness of Superhard Transition-Metal Borides: Molybdenum-Doped Tungsten Tetrabor-ide. Chem. Mater. 2016, 28, 632-637.

(17) Yeung, M. T.; Lei, J.; Mohammadi, R.; Turner, C. L.; Wang, Y.; Tolbert, S. H.; Kaner, R. B. Superhard Monoborides: Hardness Enhancement through Alloying in $\mathrm{W}_{1-\mathrm{x}} \mathrm{Ta}_{\mathrm{x}}$ B. Adv. Mater. 2016, 28, 6993-6998.

(18) Akopov, G.; Yeung, M. T.; Kaner, R. B. Rediscovering the Crystal Chemistry of Borides. Adv. Mater. 2017, 29, 1604506.

(19) Glavee, G. N.; Klabunde, K. J.; Sorensen, C. M.; Hadjapanayis, G. C. Borohydride Reductions of Metal Ions. A New Understanding of the Chemistry Leading to Nanoscale Particles of Metals, Borides, and Metal Borates. Langmuir 1992, 8, 771-773.

(20) Liu, Y.-C.; Chen, Y.-W. Hydrogenation of P Chloronitroben-zene on Lanthanum-Promoted NiB Nanometal Catalysts. Ind. Eng. Chem. Res. 2006, 45, 2973-2980.

(21) Holbrook, K. A.; Twist, J. Hydrolysis of the Borohydride Ion Catalysed by Metal-boron Alloys. J. Chem. Soc. A 1971, 0, 890-894.

(22) Demirci, U. B.; Miele, P. Cobalt in NaBH4 Hydrolysis. Phys. Chem. Chem. Phys. 2010, 12, 14651-14665.

(23) Vrubel, H.; Hu, X. Molybdenum Boride and Carbide Catalyze Hydrogen Evolution in Both Acidic and Basic Solutions. Angew. Chem., Int. Ed. 2012, 51, 12703-12706.

(24) McCrory, C. C. L.; Jung, S.; Ferrer, I. M.; Chatman, S. M.; Peters, J. C.; Jaramillo, T. F. Benchmarking Hydrogen Evolving Reaction and Oxygen Evolving Reaction Electrocatalysts for Solar Water Splitting Devices. J. Am. Chem. Soc. 2015, 137, 4347-4357.

(25) Masa, J.; Weide, P.; Peeters, D.; Sinev, I.; Xia, W.; Sun, Z.; Somsen, C.; Muhler, M.; Schuhmann, W. Amorphous Cobalt Boride $\left(\mathrm{Co}_{2} \mathrm{~B}\right)$ as a Highly Efficient Nonprecious Catalyst for Electrochemical

Water Splitting: Oxygen and Hydrogen Evolution. Adv. Energy Mater.

2016, 6, 1502313-1502323.

(26)Park, H.; Encinas, A.; Scheifers, J. P.; Zhang, Y.; Fokwa, B. P. T. Boron-Dependency of Molybdenum Boride Electrocatalysts for the Hydrogen Evolution Reaction. Angew. Chem., Int. Ed. 2017, 56, 5575- 5578.

(27)Arzac, G. M.; Rojas, T. C.; Fernandez', A. Boron Compounds as Stabilizers of a Complex Microstructure in a Co-B-Based Catalyst for $\mathrm{NaBH}_{4}$ Hydrolysis. ChemCatChem 2011, 3, 1305-1313.

(28)Chen, L.; Gu, Y.; Shi, L.; Yang, Z.; Ma, J.; Qian, Y. Synthesis and Oxidation of Nanocrystalline $\mathrm{HfB}_{2}$. J. Alloys Compd. 2004, 368, 353-356.
(29)Schaefer, Z. L.; Ke, X.; Schiffer, P.; Schaak, R. E. Direct Solution Synthesis, Reaction Pathway Studies, and Structural Characterization of Crystalline $\mathrm{Ni}_{3} \mathrm{~B}$ Nanoparticles. J. Phys. Chem. C 2008, 112, 19846- 19851. (30) Terlan, B.; Levin, A. A.; Börrnert, F.; Zeisner, J.; Kataev, V.; Schmidt, M.; Eychmüller, A. A SizeDependent Analysis of the Structural, Surface, Colloidal, and Thermal Properties of $\mathrm{Ti}_{1-\mathrm{x}} \mathrm{B}_{2}(\mathrm{x}=0.03-0.08)$ Nanoparticles. Eur. J. Inorg. Chem. 2016, 2016, 34603468.

(31) Hofmann, K.; Kalyon, N.; Kapfenberger, C.; Lamontagne, L.; Zarrini, S.; Berger, R.; Seshadri, R.; Albert, B. Metastable $\mathrm{Ni}_{7} \mathrm{~B}_{3}$ : A New Paramagnetic Boride from Solution Chemistry, Its Crystal Structure and Magnetic Properties. Inorg. Chem. 2015, 54, 1087310877 .

(32) Allard, L. F.; Overbury, S. H.; Bigelow, W. C.; Katz, M. B.; Nackashi, D. P.; Damiano, J. Novel MEMS-Based Gas-Cell/Heating Specimen Holder Provides Advanced Imaging Capabilities for In Situ Reaction Studies. Microsc. Microanal. 2012, 18, 656-666.

(33)Zhang, S.; Chen, C.; Cargnello, M.; Fornasiero, P.; Gorte, R. J.; Graham, G. W.; Pan, X. Dynamic Structural Evolution of Supported Palladium-Ceria Core-shell Catalysts Revealed by in Situ Electron Microscopy. Nat. Commun. 2015, 6, 7778.

(34) Starr, E.; Liu, Z.; Havecker, M.; Knop-Gericke, A.; Bluhm, H. Investigation of Solid/vapor Interfaces Using Ambient Pressure X-Ray Photoelectron Spectroscopy. Chem. Soc. Rev. 2013, 42, 5833-5857.

(35)Choi, S.; Lapitan, L. D. S.; Cheng, Y.; Watanabe, T. Synthesis of Cobalt Boride Nanoparticles Using RF Thermal Plasma. Adv. Powder Technol. 2014, 25, 365-371.

(36) Wu, C.; Wu, F.; Bai, Y.; Yi, B.; Zhang, H. Cobalt Boride Catalysts for Hydrogen Generation from Alkaline $\mathrm{NaBH}_{4}$ Solution.

Mater. Lett. 2005, 59, 1748-1751.

(37) Sarma, D. D.; Santra, P. K.; Mukherjee, S.; Nag, A. X-Ray Photoelectron Spectroscopy: A Unique Tool To Determine the Internal Heterostructure of Nanoparticles. Chem. Mater. 2013, 25, 1222-1232.

(38) Carenco, S.; Tuxen, A.; Chintapalli, M.; Pach, E.; Escudero, C.; Ewers, T. D.; Jiang, P.; Borondics, F.; Thornton, G.; Alivisatos, A. P.; et al. Dealloying of Cobalt from CuCo Nanoparticles under Syngas Exposure. J. Phys. Chem. C 2013, 117, 6259-6266.

(39) Carenco, S.; Wu, C.-H.; Shavorskiy, A.; Alayoglu, S.; Somorjai, G. A.; Bluhm, H.; Salmeron, M. Synthesis and Structural Evolution of Nickel-Cobalt Nanoparticles Under $\mathrm{H}_{2}$ and $\mathrm{CO}_{2}$. Small 2015, 11, 3045-3053.

(40) Polack, F.; Silly, M.; Chauvet, C.; Lagarde, B.; Bergeard, N.; Izquierdo, M.; Chubar, O.; Krizmancic, D.; Ribbens, M.; Duval, J.-P.; et al. TEMPO: A New Insertion Device Beamline at SOLEIL for Time Resolved Photoelectron Spectroscopy Experiments on Solids and Interfaces. AIP Conf. Proc. 2009, 1234, 185-188.

(41) Tissot, H.; Olivieri, G.; Gallet, J.-J.; Bournel, F.; Silly, M. G.; Sirotti, F.; Rochet, F. Cation DepthDistribution at Alkali Halide Aqueous Solution Surfaces. J. Phys. Chem. C 2015, 119, 9253-9259. 
(42)Head, A. R.; Chaudhary, S.; Olivieri, G.; Bournel, F.; Andersen, J. N.; Rochet, F.; Gallet, J.-J.; Schnadt, J. Near Ambient Pressure X-Ray Photoelectron Spectroscopy Study of the Atomic Layer Deposition of $\mathrm{TiO}_{2}$ on $\mathrm{RuO}_{2}$ (110). J. Phys. Chem. C 2016, 120, 243-251.

(43) Mavel, G.; Escard, J.; Costa, P.; Castaing, J. ESCA Surface Study of Metal Borides. Surf. Sci. 1973, 35, 109-116.

(44)Brundle, C. R.; Chuang, T. J.; Rice, D. W. X- Ray Photoemission Study of the Interaction of Oxygen and Air with Clean Cobalt Surfaces. Surf. Sci. 1976, 60, 286-300.

(45) Ennaceur, M. M.; Terreault, B. XPS Study of the Process of Oxygen Gettering by Thin Films of PACVD Boron. J. Nucl. Mater. 2000, 280, 33-38.

(46) Bellott, B. J.; Noh, W.; Nuzzo, R. G.; Girolami, G. S. Nanoenergetic Materials: Boron Nanoparticles from the Pyrolysis of Decaborane and Their Functionalisation. Chem. Commun. 2009, 3214-3215.

(47) Riedel, T.; Schaub, G. Low-Temperature Fischer-Tropsch Synthesis on Cobalt Catalysts Effects of $\mathrm{CO}_{2}$. Top. Catal. 2003, 26, 145-156.

(48) Havecker, M.; Mayer, R. W.; Knop-Gericke, A.; Bluhm, H.; Kleimenov, E.; Liskowski, A.; Su, D.; Follath, R.; Requejo, F. G.; Ogletree, D. F.; et al. In Situ Investigation of the Nature of the Active Surface of a Vanadyl Pyrophosphate Catalyst during N-Butane Oxidation to Maleic Anhydride. J. Phys. Chem. B 2003, 107, 4587-4596.

(49) Pozdnyakova, O.; Teschner, D.; Wootsch, A.; Kröhnert, J.; Steinhauer, B.; Sauer, H.; Toth, L.; Jentoft, F. C.; Knop-Gericke, A.; Paal,Z; et al. Preferential CO Oxidation in Hydrogen (PROX) on Ceria-Supported Catalysts, Part II: Oxidation States and Surface Species on $\mathrm{Pd} / \mathrm{CeO}_{2}$ under Reaction Conditions, Suggested Reaction Mechanism. J. Catal. 2006, 237, 17-28.

(50) Virnovskaia, A.; Jørgensen, S.; Hafizovic, J.; Prytz, Ø.; Kleimenov, E.; Havecker, M.; Bluhm, H.; KnopGericke, A.; Schlogl; R.; Olsbye, U. In Situ XPS Investigation of $\mathrm{Pt}(\mathrm{Sn}) / \mathrm{Mg}(\mathrm{Al}) \mathrm{O}$ Catalysts during Ethane Dehydrogenation Experiments. Surf. Sci. 2007, 601, 30-43.

(51) Behrens, M.; Studt, F.; Kasatkin, I.; Kuhl, S.; Havecker, M.; Abild-Pedersen, F.; Zander, S.; Girgsdies, F.; Kurr, P.; Kniep, B.-L.; et al. The Active Site of Methanol Synthesis over $\mathrm{Cu} / \mathrm{ZnO} / \mathrm{Al}_{2} \mathrm{O}_{3}$ Industrial Catalysts. Science 2012, 336, 893-897.

(52)Alstrup, I.; Chorkendorff, I.; Candia, R.; Clausen, B. S.; Topsoe, H. A Combined X-Ray Photoelectron and Mossbauer Emission Spectroscopy Study of the State of Cobalt in Sulfided, Supported, and Unsupported Co-Mo Catalysts. J. Catal. 1982, 77, 397-409.

(53)Joyner, D. J.; Hercules, D. M. Chemical Bonding and Electronic Structure of $\mathrm{B}_{2} \mathrm{O}_{3}, \mathrm{H}_{3} \mathrm{BO}_{3}$, and $\mathrm{BN}$ : An ESCA, Auger, SIMS, and SXS Study. J. Chem. Phys. 1980, 72, 1095 .
(54)Frazer, B. H.; Gilbert, B.; Sonderegger, B. R.; De Stasio, G. The Probing Depth of Total Electron Yield in the Sub-keV Range: TEY-XAS and X-PEEM. Surf. Sci. 2003, 537, 161-167.

(55) Li, D.; Bancroft, G. M.; Fleet, M. E. B K-Edge XANES of Crystalline and Amorphous Inorganic Materials. J. Electron Spectrosc. Relat. Phenom. 1996, 79, 71-73.

(56) Tuxen, A.; Carenco, S.; Chintapalli, M.; Chuang, C. H.; Escudero, C.; Pach, E.; Jiang, P.; Borondics, F.; Beberwyck, B.; Alivisatos, A. P.; et al. Size-Dependent Dissociation of Carbon Monoxide on Cobalt Nanoparticles. J. Am. Chem. Soc. 2013, 135, 2273-2278.

(57) Perry, D. L. Handbook of Inorganic Compounds, 2nd ed.; CRC Press, 2011.

(58)Carenco, S.; Sassoye, C.; Faustini, M.; Eloy, P.; Debecker, D. P.; Bluhm, H.; Salmeron, M. B. The Active State of Supported Ruthenium Oxide Nanoparticles during Carbon Dioxide Methanation. J. Phys. Chem. C 2016, 120, 15354-15361.

(59) Kim, A.; Sanchez, C.; Patriarche, G.; Ersen, O.; Moldovan, S.; Wisnet, A.; Debecker, D. P.; Sassoye, C. Selective $\mathrm{CO}_{2}$ Methanation on $\mathrm{Ru} / \mathrm{TiO}_{2}$ Catalyst: Unraveling the Decisive Role of the $\mathrm{TiO}_{2}$ Support Crystal Structure. Catal. Sci. Technol. 2016, 6, 8117-8128.

(60) Riva, R.; Miessner, H.; Vitali, R.; Del Piero, G. Metal-support Interaction in $\mathrm{Co} / \mathrm{SiO}_{2}$ and $\mathrm{Co} / \mathrm{TiO}_{2}$. Appl. Catal., A 2000, 196, 111- 123.

(61) Patel, N.; Fernandes, R.; Guella, G.; Kale, A.; Miotello, A.; Patton, B.; Zanchetta, C. Structured and Nanoparticle Assembled Co-B Thin Films Prepared by Pulsed Laser Deposition: A Very Efficient Catalyst for Hydrogen Production. J. Phys. Chem. C 2008, 112, 6968-6976.

(62) Saeys, M.; Tan, K. F.; Chang, J.; Borgna, A. Improving the Stability of Cobalt Fischer-Tropsch Catalysts by Boron Promotion.Ind. Eng. Chem. Res. 2010, 49, 11098-11100

(63) Lahtinen, J.; Anraku, T.; Somorjai, G. A. C, CO and $\mathrm{CO}_{2}$ Hydrogenation on Cobalt Foil Model Catalysts: Evidence for the Need of CoO Reduction. Catal. Lett. 1994, 25, 241-255

(64) Reuel, R. C.; Bartholomew, C. H. The Stoichiometries of $\mathrm{H}_{2}$ and $\mathrm{CO}$ Adsorptions on Cobalt: Effects of Support and Preparation. J. Catal. 1984, 85, 63-77.

(65) McCue, I.; Benn, E.; Gaskey, B.; Erlebacher, J. Dealloying and Dealloyed Materials. Annu. Rev. Mater. Res. 2016, 46, 263-286Z.

(66) Tanuma, S.; Powell, C. J.; Penn, D. R. Calculations of Electron Inelastic Mean Free Paths. V. Data for 14 Organic compounds Over The 50-2000 eV Range. Surf. Interface Anal. 1994, 21, 165-176. 



\section{Supplementary information}

\section{In situ solid-gas reactivity of nanoscaled}

\section{metal borides from molten salt synthesis}

Guillaume Gouget $^{a, \dagger}$, Damien P. Debecker ${ }^{b}$, Ara Kim $^{a, b}$, Giorgia Olivieri $^{c}$, Jean-Jacques $^{\prime}$

Gallet $^{c, d}$, Fabrice Bournel ${ }^{c, d}$, Cyril Thomas $^{e}$, Ovidiu Ersen ${ }^{f}$, Simona Moldovan, ${ }^{f}$, Clément Sanchez $^{a}$, Sophie Carenco ${ }^{a}$ and David Portehault ${ }^{a}$

${ }^{a}$ Sorbonne Universités-UPMC Univ. Paris 06, CNRS, Collège de France, Laboratoire de Chimie de la Matière Condensée de Paris, 4 place Jussieu, F-75252 Paris Cedex 05, France.

${ }^{\mathrm{b}}$ Université catholique de Louvain, Institute of Condensed Matter \& Nanosciences, Molecules, Solids \& Reactivity, Place Louis Pasteur 1, 1348 Louvain-la-Neuve, Belgium.

${ }^{c}$ Synchrotron SOLEIL, L'Orme des Merisiers, Saint-Aubin, BP 48, 91192 Gif sur Yvette Cedex, France.

${ }^{\mathrm{d}}$ Sorbonne Universités, UPMC Univ Paris 06, Laboratoire de Chimie Physique, Matière et Rayonnement, 4 place Jussieu, F-75252 Paris Cedex 05, France.

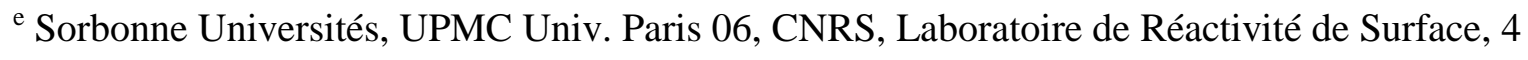
place Jussieu, F-75252 Paris Cedex 05, France.

${ }^{\mathrm{f}}$ Institut de Physique et Chimie des Matériaux de Strasbourg, CNRS, 23 Rue Loess, BP 43, F67034 Strasbourg, France. 


\section{Methods}

Figure S1. In situ TEM analysis of the CoB nanocomposite under (a) 0.3 bar of argon at $150{ }^{\circ} \mathrm{C}$, and (b) 0.9 bar of $\mathrm{H}_{2}$ at $400{ }^{\circ} \mathrm{C}$.

Figure S2. XPS surveys of the CoB nanocomposite at various steps of the in situ study.

Figure S3. Methane production rate as a function of temperature for various samples after $20 \mathrm{~min}$ on stream.

Figure S4. XRD diagrams of $\mathrm{CoB}$ supported on $\mathrm{TiO}_{2}$ at different steps of the methanation.

Figure $\mathrm{S5} \mathrm{CH} 4$ production rate as a function of time on stream for $\mathrm{SiO}_{2}$ - and $\mathrm{TiO}_{2}$-supported $\mathrm{CoB}$ at 400 and $500{ }^{\circ} \mathrm{C}$.

Figure S6. Powder XRD patterns of the $\mathrm{CoB}$ nanocomposite supported on $\mathrm{SiO}_{2}$ before exposure to the reducing treatment and after different steps of the catalytic process.

Figure S7. Powder XRD patterns of $\mathrm{CoB}$ nanoparticles before and after heat treatment under $\mathrm{H}_{2}: \mathrm{Ar}$ (5:95 volume ratio). 


\section{Techniques}

Powder X-ray diffraction (XRD). XRD measurements were performed on a D8 Bruker apparatus operating at the $\mathrm{Cu}-\mathrm{K} \alpha$ radiation. Patterns were indexed according to ICDD files: $\mathrm{CoB}$ (04-003-2122), cubic Co (04-001-2681), hexagonal Co (04-01-3273), $\mathrm{Co}_{3} \mathrm{O} 4$ (04-05-4386), NiB (01-074-1207), Ni4B 3 (01-073-2551), Ni3 B (04-014-0853) and Ni (04-010-6148). Apparent crystallite sizes were calculated using the Scherrer formula and pseudo -Voigt functions to fit peaks. The samples after the pretreatments and the catalytic reactions were extracted and analyzed by XRD in inert atmosphere using a glovebag filled with nitrogen and a protective sample holder.

Transmission electron microscopy (TEM). A $120 \mathrm{kV}$ Tecnai Spirit microscope was used for TEM. High Resolution-TEM (HRTEM) was also operated on a 200 kV JEOL JEM 2011 apparatus, at the Institut des Matériaux de Paris Centre (IMPC). Samples were prepared by evaporating a drop of suspension in ethanol on a carbon-coated copper grid. SAED pictures were calibrated with gold nanoparticles.

Energy Dispersive X-Ray spectrometry (EDX). Elemental EDX analyses were obtained on a Scanning Electron Microscope (SEM) S -3400-N (Hitachi) equipped with an EDX detector (Oxford) calibrated prior measurements to allow retrieving quantitative data. $100 \times 50 \mu \mathrm{m}^{2}$ areas were probed. Acceleration tension of the source was $10 \mathrm{kV}$. A titanium grid was used for quantitative calibration. The samples were fixed to a conductive carbon tape.

Inductive coupled plasma-Optical Emission Spectrometry. ICP-OES measurements were acquired on an iCAP 6000 apparatus (ThermoFischer). The sample was prepared by dissolving the cobalt boride powder in a $5 \mathrm{~mol} \mathrm{~L}^{-1}$ nitric acid solution followed by a 10 times dilution in deionized water. Each concentration is the average of three measurements.

Nitrogen sorption. Samples were degassed at $150{ }^{\circ} \mathrm{C}$ overnight before measuring on an ASAP 2000 apparatus (Micromeritics). 

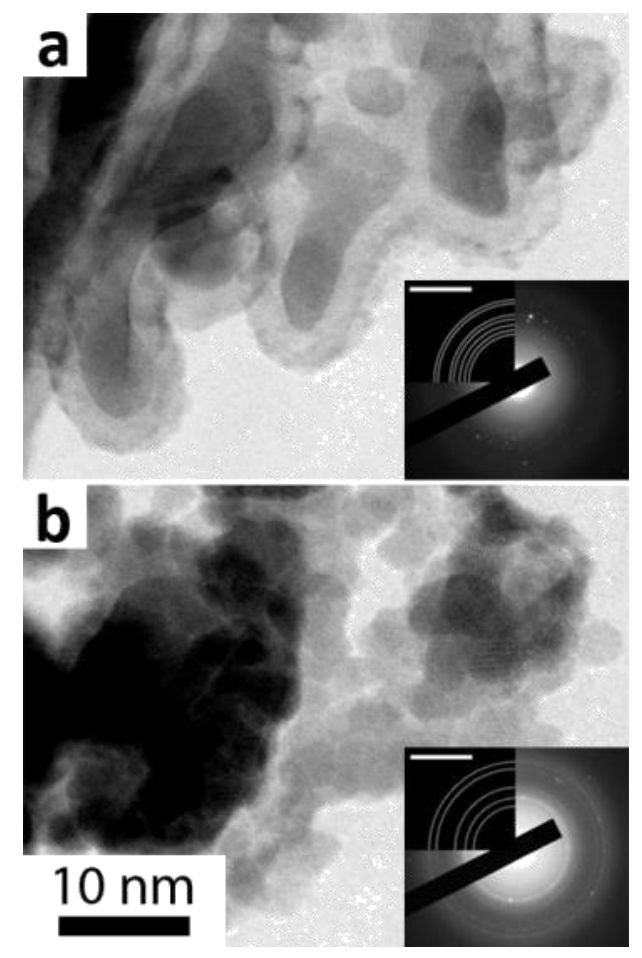

Figure S1. In situ TEM analysis of the $\mathrm{CoB}$ nanocomposite under (a) 0.3 bar of argon at $150{ }^{\circ} \mathrm{C}$, and (b) 0.9 bar of $\mathrm{H}_{2}$ at $400{ }^{\circ} \mathrm{C}$. The SAED patterns are indexed (a) along the $\mathrm{CoB}$ structure and (b) along the $\mathrm{Co}_{3} \mathrm{O}_{4}$ structure. Note that the surprising occurrence of $\mathrm{Co}_{3} \mathrm{O}_{4}$, contrary to UHV-XPS, NAP-XPS and $e x$ situ XRD, arises from the very small gas flow and non-optimized gas inlet used in this apparatus, that likely resulted in traces of oxygen impurities in the flow. 


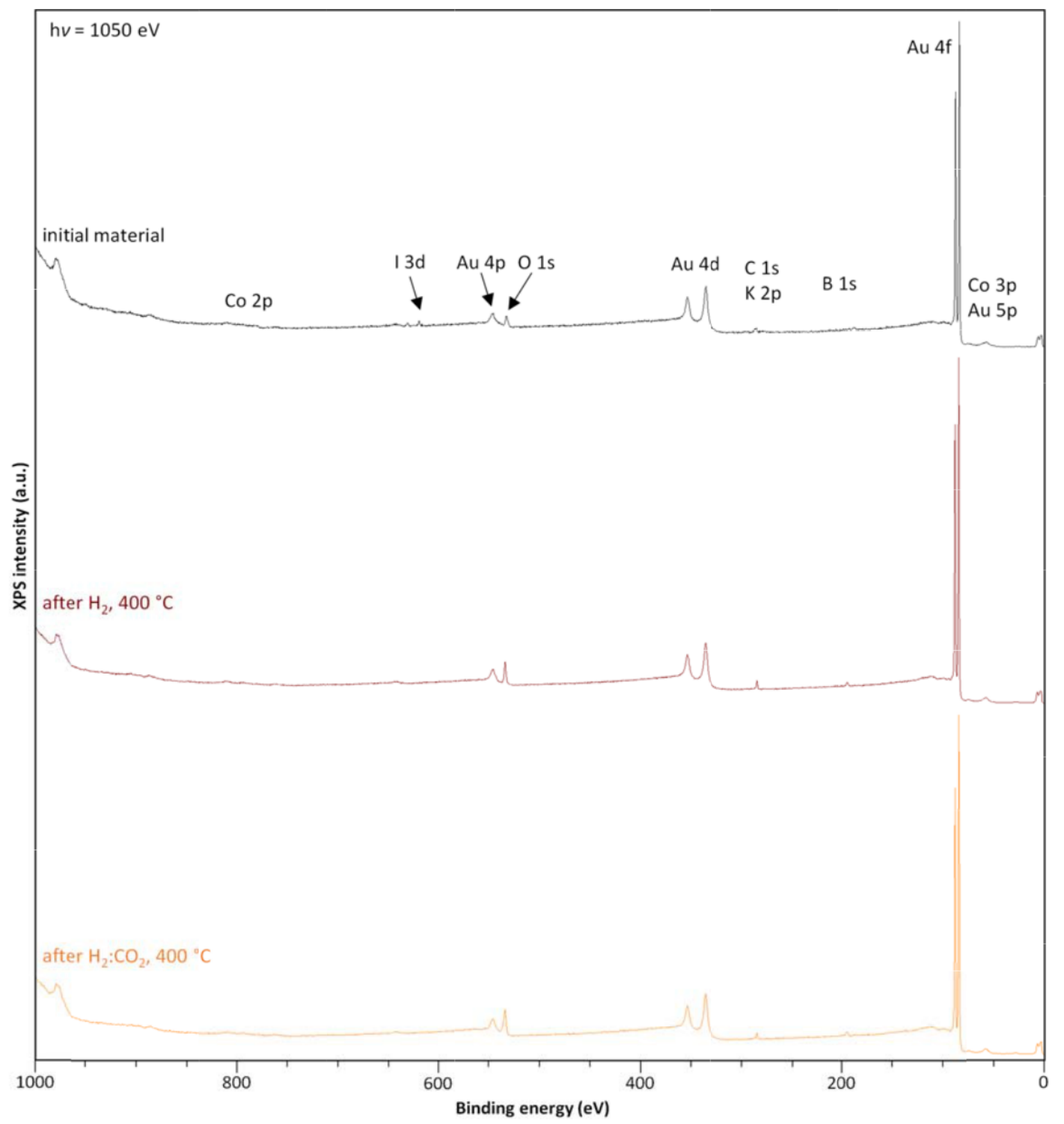

Figure S2. UHV-XPS surveys of the initial CoB nanocomposite (black), after exposure to 1 bar of $\mathrm{H}_{2}$ at $400{ }^{\circ} \mathrm{C}$ in UHV (maroon) and after exposition to $\mathrm{H}_{2}: \mathrm{CO}_{2}$ (4:1 vol.) at $400{ }^{\circ} \mathrm{C}$. hv: photon energy. Potassium and iodine are detected only in the initial material. These impurities come from the inorganic salt medium in which the nanocomposite is synthetized. These elements were not detected by MEB-EDX. They are thus present in very sm all proportion, are located only at the surface and eliminated during the first heat treatment.

Note that after NAP-XPS experiments and return to room temperature and UHV conditions, two other species are detected by XPS ("BOx" on Figure 4 in the main text). Indeed, two oxygen contributions appear at 536.9 and $537.9 \mathrm{eV}$. In the B 1s region under UHV conditions, two peaks at 197.1 and $198.1 \mathrm{eV}$ appear in addition to the $\mathrm{BO}_{3}$ peak at $195.4 \mathrm{eV}$. The area ratios between the two oxygen peaks and 
between the two boron peaks are identical. The four contributions are thus interlinked, with couples $(\mathrm{O} 1 \mathrm{~s}$, B 1s) attributed to two unusual fully oxidized boron species with binding energies that are much higher than any other reported previously.(M. M. Ennaceur, B. Terreault, XPS Study of the Process of Oxygen Gettering by Thin Films of PACVD Boron. J. Nucl. Mater. 2000, 280, 33-38; B. R. Strohmeier, Surface Characterization Of Ammonium Fluoborate. 1989, 40, 249-263)

When the material is heated again under NAP conditions (data not shown), these two species disappear and the NAP-XPS spectra are found similar to those shown in Figure 4, red spectra, thus indicating the reversibility of such structural changes under UHV conditions. These high-energy peaks may originate from locally distorted boron oxides only stable under UHV conditions. Similar phenomena have been described during the reduction of cerium oxides.(J. Holgado, G. Munuera, J. Espinós, A. González-Elipe, XPS Study of Oxidation Processes of $\mathrm{CeO}_{\mathrm{x}}$ Defective Layers. Appl. Surf. Sci. 2000, 158, 164-171) These UHV metastable species are not representative of the material exposed to environmental conditions and have not been further investigated. 


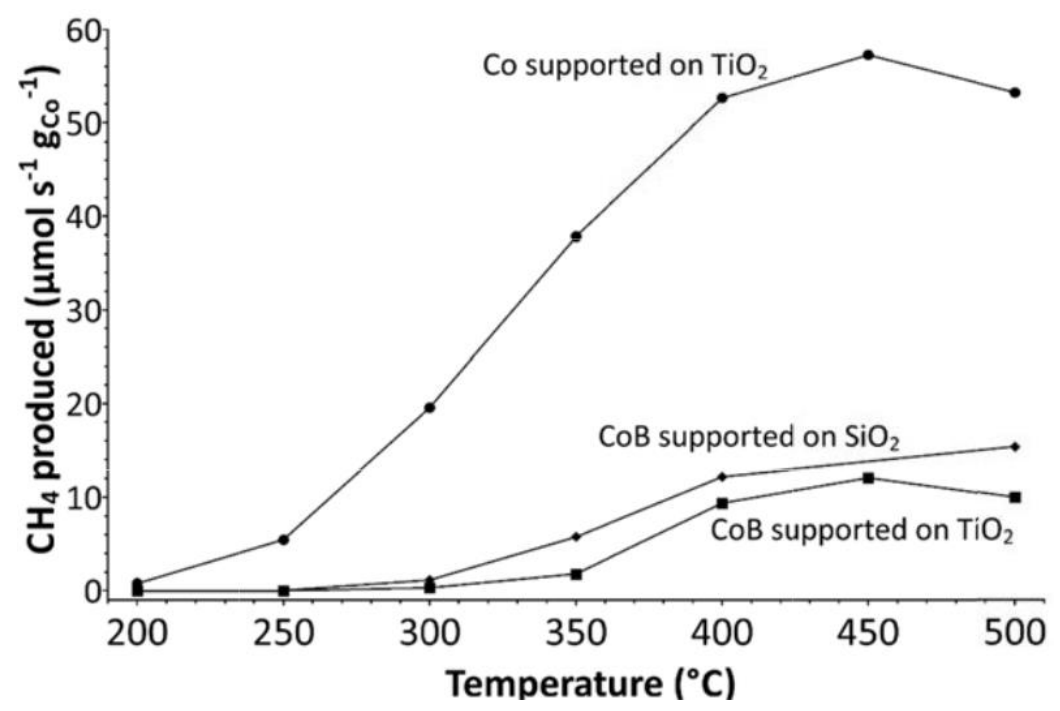

Figure S3. Methane production rate as a function of te mperature for various samples after $20 \mathrm{~min}$ on stream. Supported $\mathrm{CoB}$ were treated under $\mathrm{H}_{2}\left(1 \mathrm{~atm}, 30 \mathrm{~mL} \mathrm{~min}^{-1}\right)$ at $400{ }^{\circ} \mathrm{C}$. The reactive gas mixture during the methanation reaction was $\mathrm{CO}_{2}: \mathrm{H}_{2}: \mathrm{He}$ (vol. ratio 1:4:5, $1 \mathrm{~atm}, 20 \mathrm{~mL} \mathrm{~min}^{-1}$ ).

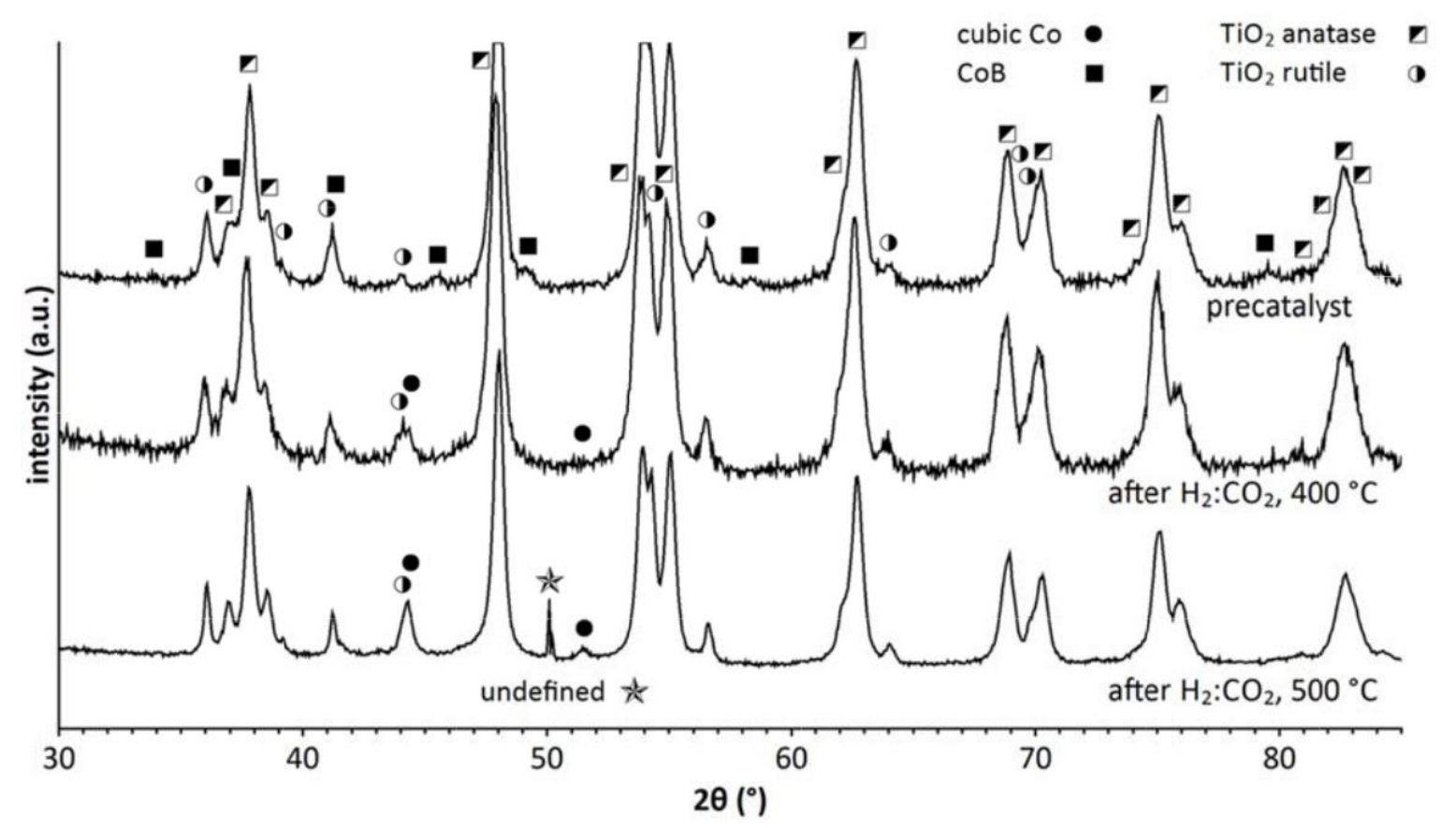

Figure S4. XRD patterns of $\mathrm{CoB}$ supported on $\mathrm{TiO}_{2}$ at different steps. The anatase and rutile phases of $\mathrm{TiO}_{2}$ are indexed according to the ICDD files 00-021-1272 and 00-021-1276, respectively. 


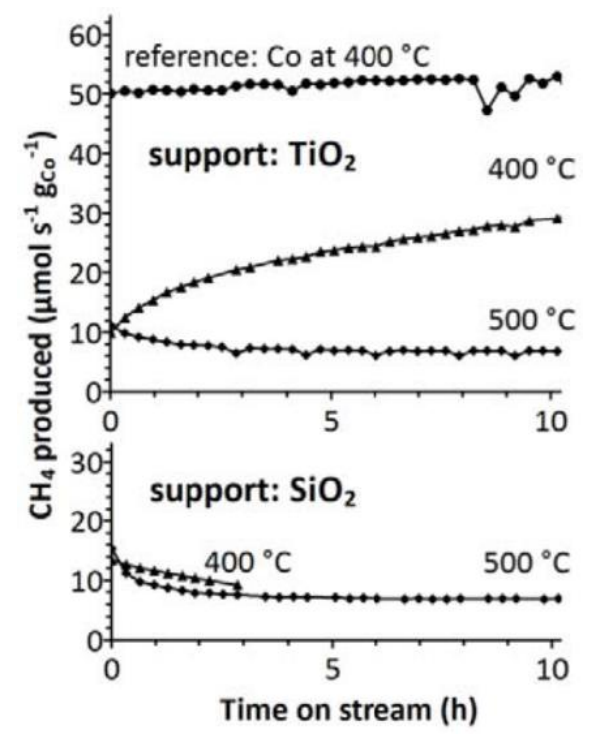

Figure S5. $\mathrm{CH}_{4}$ production rate as a function of time on stream for $\mathrm{SiO}_{2}-$ and $\mathrm{TiO}_{2}$-supported $\mathrm{CoB}$ at 400 and $500{ }^{\circ} \mathrm{C}$. The behavior of a $\mathrm{Co} / \mathrm{TiO}_{2}$ reference sample is also shown for comp arison. Inner gas mix: $\mathrm{H}_{2}: \mathrm{CO}_{2}: \mathrm{He}$ (4:1:5 vo 1.), $1 \mathrm{~atm}, 20 \mathrm{~mL} \mathrm{~min}^{-1}$. P retreatment: $\mathrm{H}_{2}, 1 \mathrm{~atm}, 30 \mathrm{~mL} \mathrm{~min}^{-1}$ at $400{ }^{\circ} \mathrm{C}$ for $2 \mathrm{~h}$. For $\mathrm{CoB}$ sup ported on $\mathrm{SiO}_{2}$, the $\mathrm{CH}_{4}$ production rate decreases upon time on stream, leading to a 2-fold decrease at $500{ }^{\circ} \mathrm{C} \mathrm{w}$ ithin $2 \mathrm{~h}$ on stream. Then the rate reaches steady state at around $7 \mathrm{~mol} \mathrm{~s}^{-1} \mathrm{gCo}^{-1}$.

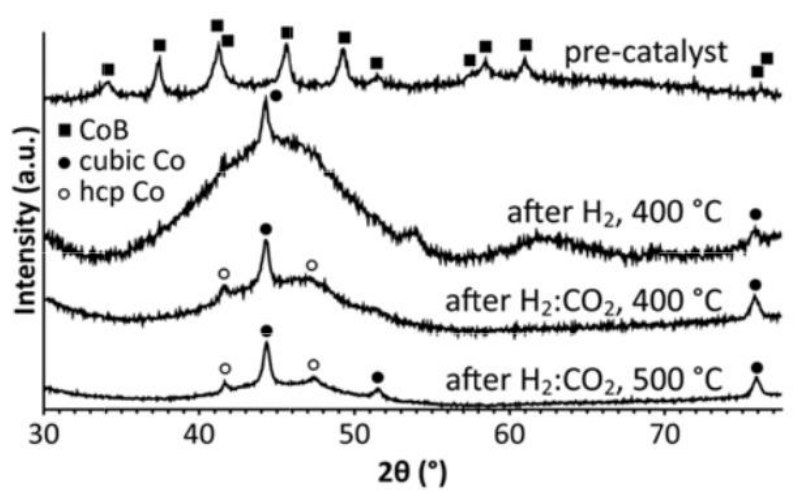

Figure S 6. Powder XRD patterns of the $\mathrm{CoB}$ nanocomposite supported on $\mathrm{SiO}_{2}$ before exposure to the reducing treatment and after different steps of the catalytic process. In the initial state, the XRD pattern is similar to that recorded for the unsupported material (Figure 1a in the main text), with broad peaks corresponding to $\mathrm{CoB}$ nanoparticles and crystallite sizes of $14 \pm 3 \mathrm{~nm}$ according to the Scherrer formula. After exposure to $\mathrm{H}_{2}$ at $400{ }^{\circ} \mathrm{C}$ for $2 \mathrm{~h}, \mathrm{CoB}$ reflections disappear, whereas peaks corresponding to cubic Co are detected, in agreement with UHV-XPS and NEXA FS data, with an apparent diameter of $18 \pm 4 \mathrm{~nm}$. A broad contribution to the baseline is observed in addition to crystalline Co, indicatin $\mathrm{g}$ that the amorphous part of the material has evolv ed compared to the pre-catalyst. A fter exposure to the methanation conditions at $400{ }^{\circ} \mathrm{C}$ for $3 \mathrm{~h}$, metallic cobalt is also observed in the cubic and hexagonal structures with a crystallite size of $15 \pm 2 \mathrm{~nm}$. After methanation at $500{ }^{\circ} \mathrm{C}$, the presence of cubic and hexagonal Co crystallites is also identified with the same apparent size. 


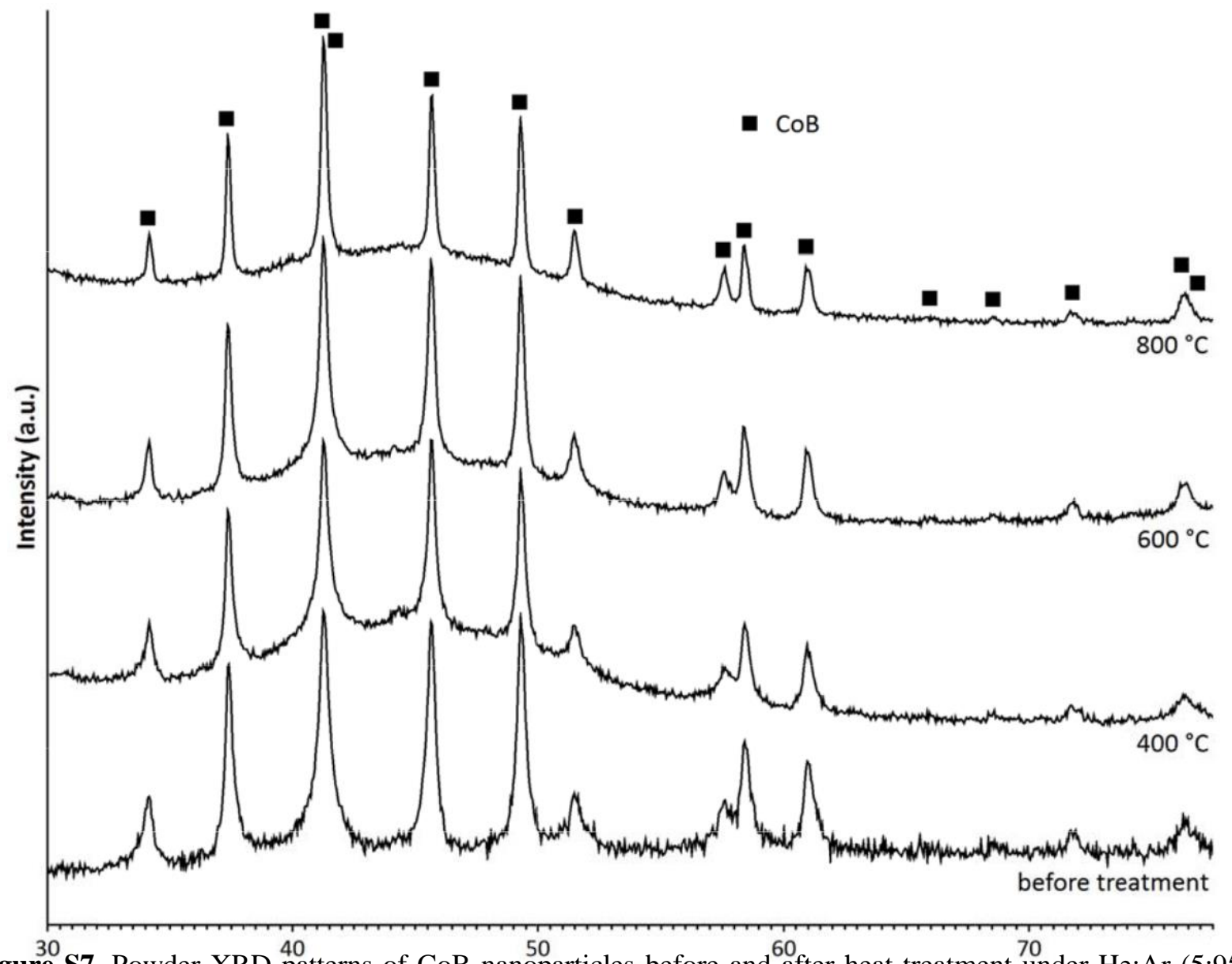

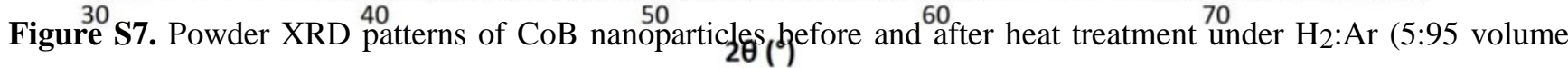
ratio) at various temperatures for $2 \mathrm{~h}$. Heat treatments in a mix of argon and dihydrogen (5\%) do not lead to cobalt boride decompositions. $\mathrm{CoB}$ remains the only crystalline phase detected, even after heating at $800{ }^{\circ} \mathrm{C}$. Reflections sharpen with increasing temperature due to nanocrystal growth. 